\title{
What are the effects of flow-regime changes on fish productivity in temperate regions? A systematic map
}

Trina Rytwinski 1,2,3* , Meagan Harper ${ }^{1,2,3}$, Jessica J. Taylor ${ }^{1,2}$, Joseph R. Bennett ${ }^{1,3}$, Lisa A. Donaldson 1,2, Karen E. Smokorowski ${ }^{4}$, Keith Clarke ${ }^{5}$, Michael J. Bradford ${ }^{6}$, Haitham Ghamry ${ }^{7}$, Julian D. Olden ${ }^{8}$, Daniel Boisclair ${ }^{9}$ and Steven J. Cooke $e^{1,2,3}$

\begin{abstract}
Background: There is growing evidence of the potential negative consequences of altered flow regimes, in terms of magnitude, frequency, timing, duration or season pattern, on fluvial ecosystems and the fisheries they support. The scientific and policy communities have acknowledged the need for a better understanding of the effects of flow alteration on fish productivity. We conducted a systematic map to provide an overview of the existing literature base on the effects of flow-regime changes on direct outcomes of freshwater or estuarine fish productivity in temperate regions to inform stakeholders and policy makers.

Methods: To identify relevant articles for inclusion in this systematic map, we searched six bibliographic databases, 29 organizational websites, one search engine, and 297 reviews, and solicited grey literature through relevant sources. We screened articles at title and abstract, then by full-text using predefined inclusion criteria. Included studies were coded for key variables of interest, along with a very basic critical appraisal for internal validity (i.e., susceptibility to bias). The quantity and characteristics of the available evidence, knowledge gaps and subtopics with sufficient coverage for full systematic reviewing are reported in a narrative synthesis. The distribution and frequency of examined effects of flow-regime changes on fish productivity outcomes are presented in visual heatmaps.

Review findings: A total of 1368 studies from 1199 articles were included in the systematic map database and used to identify a number of interesting themes in the evidence base: (1) large evidence bases were found in temperate regions of United States of America (USA), Canada, and Australia; (2) most studies either used a temporal or spatial trend design i.e., lacking a 'true' before intervention time period, or no intervention control sites; (3) the most studied causes of altered flow regime were natural (e.g., floods, droughts, climate change), hydroelectric facilities (hydro), and dams with no hydro; and (4) there were clear clusters of studies evaluating effects of changes in magnitude and surrogate measures (e.g., velocity, water depth) on fish productivity outcomes, in particular abundance and diversity metrics. A number of potential knowledge gaps were identified: including geographic (Northern Africa, and possibly parts of Asia), causes of altered flow regime (restoration, land-use change, and water abstraction/extraction/diversion), interventions (flow duration, frequency, rate of change, or timing), outcomes (population viability) and specific intervention/cause/outcome groups (e.g., changes in flow magnitude due to hydro or natural causes and fish survival,
\end{abstract}

\footnotetext{
*Correspondence: trytwinski@hotmail.com

${ }^{1}$ Canadian Centre for Evidence-Based Conservation, Institute

of Environmental and Interdisciplinary Science, Carleton University,

Ottawa, ON, Canada

Full list of author information is available at the end of the article
}

c) The Author(s) 2020. This article is licensed under a Creative Commons Attribution 4.0 International License, which permits use, sharing, adaptation, distribution and reproduction in any medium or format, as long as you give appropriate credit to the original author(s) and the source, provide a link to the Creative Commons licence, and indicate if changes were made. The images or other third party material in this article are included in the article's Creative Commons licence, unless indicated otherwise in a credit line to the material. If material is not included in the article's Creative Commons licence and your intended use is not permitted by statutory regulation or exceeds the permitted use, you will need to obtain permission directly from the copyright holder. To view a copy of this licence, visit http://creativeco mmons.org/licenses/by/4.0/. The Creative Commons Public Domain Dedication waiver (http://creativecommons.org/publicdomain/ zero/1.0/) applies to the data made available in this article, unless otherwise stated in a credit line to the data. 
performance, and reproduction). A few aspects in methodology were also identified across studies, primarily a lack of true comparators (e.g., temporal or spatial trend designs).

Conclusions: This map suggests subtopics warranting future evidence synthesis include, examinations into how changes in flow magnitude affects: (1) fish abundance for dams with no hydro causes; (2) fish abundance, diversity/ richness, migration, and growth for hydro causes; and (3) fish abundance, diversity/richness, growth, community structure, recruitment, and migrating fish abundance for natural causes. More comprehensive evidence is needed to understand how: (1) fish productivity metrics are affected by changes in flow regime due to restoration, land-use change, and water withdrawal/diversion activities; (2) how fish productivity is affected by changes to components of flow regime other than magnitude (e.g., flow duration, frequency); and (3) changes in flow magnitude due to hydro or natural causes affect fish survival, performance, and reproduction; and (4) changes in flow regime (all causes, all interventions) affect population viability.

Keywords: Dam, Evidence-based policy, Fish biomass, Fish abundance, Fish density, Flow modification, Hydroelectric, Reservoirs, River regulation, Stream

\section{Background}

The importance of the hydrologic regime for shaping the biophysical attributes and function of rivers is well recognized [1-5]. The natural flow paradigm stresses that intra- and interannual patterns in river discharge-the flow regime describing the magnitude, frequency, duration, timing, and rate of change of flow events-play a direct or indirect role in maintaining the ecological integrity of the aquatic system [2]. Over evolutionary time, aquatic communities, including fish populations, have adapted to the inherent natural variability of rivers and streams [6] and selected for different life history strategies over many generations [7]. The importance of this natural flow variability in maintaining healthy fluvial ecosystems has recently become a primary focus for water resource managers, indicating the need for a better understanding of flow-ecosystem response relationships for effective management of these systems [8].

Many freshwater ecosystems are under increasing threat from anthropogenic activities and escalating human demands for water, which has led to alterations and changes of natural flow regimes [9]. Flow alterations can result from many human modifications, including the construction of dams, hydroelectric facilities, water extraction for agriculture, water abstraction, drinking, industry, and recreation, and flood-control measures [10, 11]. Such changes of the natural flow regime may impact various chemical, physical, hydraulic, geomorphological, and biological attributes of rivers leading to declines in water quality, water supply, and the ecological integrity of river and stream ecosystems [3]. For example, in a review of the ecological effects of altered flow regimes, Poff and Zimmerman [12] reported that $92 \%$ of studies reported reductions in ecological metrics (e.g., changes in species or population abundance, demographic rates or community diversity for various taxonomic groups) in response to flow alterations resulting from a host of human activities.

Changes to extreme hydrologic events (e.g., floods and droughts) can cause significant effects on freshwater ecosystems. Increases in flow magnitude due to flooding result in the displacement or death of stream biota and can alter their habitat in numerous ways, but can also provide increased connectivity between isolated waterbodies [13, 14]. Decreases in flow magnitude in response to drought causes inhabitants to occupy smaller more isolated areas of habitat where biotic interactions may intensify, and changes to fish communities may ensue [14]. Effects of hydrological extreme events are noted to be highly variable and context dependent, and reliant upon event magnitude, duration, pattern, and timing relative to life cycles of the resident species [14-16]. For example, McManamay et al. [17] reported mostly negative responses of fish and invertebrates to droughts, and variable and non-consistent responses to floods in a meta-analysis of studies from the South Atlantic Region of the United States (USA). By contrast, Piniweski et al. [18] found a lack of significance for the effect of floods on fish metrics (abundance, density, diversity and richness) in Europe, but was unable to synthesize fish responses to drought due to a lack of available evidence. Understanding the ecological effects of these natural extremes is necessary for effective management of freshwater systems.

Ecosystem changes from altered or changed flows can have multiple effects on freshwater fishes, including changes to physical habitat, habitat access, food supplies, behaviour, community composition, energy expenditure, and population dynamics $[19,20]$. Fish abundance, demographic parameters, and diversity were found to consistently decline in response to both increases and decreases in flow magnitude (reviewed in Poff and Zimmerman [12] but also see Webb et al. [21]). Modifications of flows from natural regimes were associated with 
reduced abundance of fluvial specialists but not habitat generalists (reviewed in Haxton and Findlay [22]). Fish productivity is also affected by management actions that seek to restore or control flow to rivers impacted by hydroelectric facilities. For example, in Newfoundland, the placement of hydraulic control structures on a $1.2 \mathrm{~km}$ long natural high flow, flood bypass channel of the Rose Blanche River provided constant regulated flow to an area that was previously only wetted during snow melt events. Monitoring of the effects of this controlled flow over 3 years showed a steady increase in total fish biomass (an indicator of productivity) in the channel each year [23].

\section{Topic identification and stakeholder input}

Given mounting evidence for the effects of altered flow regimes on fish, there is currently a strong consensus within the scientific and policy communities that maintaining or restoring, as close as possible, natural flow variability, is important for sustaining ecological health of rivers ecosystems and the fisheries they support (e.g., $[2,24-26])$. However, for water resource managers, decisions on the potential effects of flow alterations on fish productivity are difficult because there are still uncertainties in our understanding of flow-fish productivity relationships. As a result, a review of the effects of flow alteration on fish productivity has been explicitly proposed by Canadian stakeholders [i.e., Fisheries and Oceans Canada (DFO)]. Due to the wide scope of such a review, and the diversity of fish productivity outcomes used to evaluate flow alteration effects, the potential set of studies to consider was quite heterogeneous. Therefore, prior to undertaking a comprehensive and quantitative synthesis, we begin with a systematic map to provide an overview of the existing literature base on the effects of flow-regime changes on fish productivity in freshwater and estuarine fluvial environments. We also use this systematic map to identify subtopics that are sufficiently covered by existing studies to allow full systematic reviewing.

During the formulation of the review question, an Advisory Team made up of stakeholders and experts was established and consulted. This team included academic scientists from Canada and USA, and staff from DFO, specifically the Fish and Fish Habitat Protection Program (FFHPP), and Science Branch. The Advisory Team guided the focus of this review to ensure the primary question was both answerable and relevant, and suggested search terms to capture the relevant literature. The Advisory Team was also consulted in the development of the inclusion criteria for article screening and the list of specialist websites for searches, and provided feedback on the final manuscript.

\section{Objective of the review}

The systematic map was intended to provide an overview of the existing body of literature addressing the effects of flow alteration on fish productivity in freshwater and estuarine fluvial environments. Our primary research question was: what are the effects of flow-regime changes on fish productivity in temperate regions? Through this systematic mapping exercise, we describe the quantity and key characteristics (e.g., study design types, interventions examined, outcomes measured, geographical locations, and fish taxonomic groups studied) of the available evidence, identify evidence clusters, and knowledge gaps. The systematic map also identifies subtopics that are sufficiently covered by existing studies to allow full systematic reviewing.

To address our primary question, the systematic map was based on the following study components:

- Subject (population): Freshwater and estuarine fish in temperate regions.

- Intervention/exposure: Changes to (or manipulations of) flow regime.

- Comparator: No intervention or alternative levels of intervention (broadly defined).

- Outcomes: Change in a component of fish productivity (broadly defined in terms of: biomass, abundance, density, yield, diversity, growth, survival, individual performance, migration, reproduction, recruitment, or a surrogate thereof).

\section{Methods}

This map followed detailed methods described in the a priori systematic map protocol Rytwinski et al. [27], and was performed according to the guidelines provided by the Collaboration for Environmental Evidence [28]. Any deviations from the protocol are highlighted in the sections below.

\section{Search for articles}

This systematic map was based on literature searches conducted in July 2017 using six publication databases accessed using Carleton University's institution subscriptions: (1) Web of Science (Core Collection), (2) ProQuest Dissertations \& Theses Global, (3) Scopus, (4) Federal Science Library (DFO and others library catalogue only; formally known as WAVES), (5) Science.gov, and (6) AGRICOLA (see Additional file 1 for detailed search methods, including citation indices considered in each database, and results). We searched one search engine (Google Scholar; using the first 500 results in July 2017), and 29 websites (Feb 2017). Search terms were limited 
to English language due to project resource restrictions. In addition, we hand searched reference sections of accepted articles and 297 relevant reviews (see Additional file 2) for any relevant titles that were not found using the search strategy. A call for evidence was also issued to target sources of grey literature through relevant mailing lists (Canadian Conference for Fisheries Research, American Fisheries Society), and through social media (Twitter, Facebook) in February and November 2017. The Advisory Team also distributed the call for evidence to relevant networks and colleagues. To ensure the relevant articles were captured by the search, our search results were checked against a benchmark list of relevant papers provided by the Advisory Team (see Additional file 1).

\section{Assembling a library of search results}

After all searches were completed and references found using the publication databases and Google Scholar were compiled, the results from each were imported into the software EPPI-Reviewer (eppi.ioe.ac.uk/eppireviewer4) as one database. Due to restrictions in exporting search results, the database results from the Federal Science Library and the AGRICOLA were screened in separate Excel spreadsheets. Prior to screening, duplicates were identified using a function in EPPI-Reviewer and then were manually removed by one reviewer (TR). One reviewer manually identified and removed any duplicates in the Federal Science Library and the AGRICOLA spreadsheets (TR). All references regardless of their perceived relevance to this systematic map were included in the database.

\section{Article screening and study eligibility criteria Screening process}

Articles found by searches in databases and Google Scholar were screened at two distinct stages: (1) title and abstract, and (2) full-text. Articles found by other means than database or search engine searches (i.e., specialist website or other literature searches) were entered at the full-text stage of this screening process but were not included in consistency checks. Any doubt over the presence of a relevant inclusion criterion (or if information is absent) resulted in the articles being retained for assessment at a later stage. Titles and abstracts were screened by four reviewers (Shannon Clarke [SC], Daniel Struthers [DS], Emily Way-Nee [EWN], and Teah Lizee [TL]). Prior to screening title and abstracts, all reviewers screened $1309 / 13,055$ articles (10\% of the articles from publication databases included in EPPI-Reviewer; not including results from Google Scholar, specialist websites or other sources of literature, or Federal Science Library and the AGRICOLA spreadsheets) for consistency checks to ensure consistent and repeatable decisions were being made among reviewers in regards to which articles got screened out and which went on in the process to be further reviewed. In a deviation from the protocol, Kappa statistics were not calculated between reviewers since there were more than two reviewers; instead, the percentage of agreements among reviewers was calculated. The reviewers agreed on $86 \%$ of the articles. Of the disagreements, $86 \%$ (i.e., 154/180 disagreements) were because one reviewer was more inclusive than the other reviewers (i.e., the one included the article when the other reviewers excluded it). Any disagreements in coding between reviewers were discussed with a fifth reviewer (TR) and a consensus decision made before moving forward. When necessary, uncertainties were discussed and resolved by the broader review team. Reviewers did not screen articles (at title and abstract or full-text) for which they were an author.

A consistency check was also conducted prior to screening articles at full-text on 150/2417 articles (6.2\% of the articles included in EPPI-Reviewer; does not include specialist websites or other sources of literature, or Federal Science Library and the AGRICOLA spreadsheets). Full-texts were screened by five reviewers (SC, EWN, TL, Laura Elmer [LE], and Jill Brooks [JB]), with a coding agreement on $81 \%$ of articles. After discussing inconsistencies, the remaining articles were split between the five reviewers and allowed to proceed. Any query made by a reviewer was discussed with a sixth reviewer (TR) and a consensus decision made, and conferred to all reviewers. If a decision for a given query could not be made by TR, uncertainties were discussed and reconciled with the broader research team. In these cases, more detailed refinements were made to the eligibility criteria to improve clarity for screening (see Table 1 for considerations identified in italic font). Lists of all articles excluded on the basis of full-text assessment with the reasons for exclusion, and unobtainable articles are provided in Additional file 2.

\section{Eligibility criteria}

All articles were screened according to the established eligibility criteria developed in consultation with the Advisory Team (Table 1). Articles were included only when all six criteria were met.

\section{Study validity assessment Study validity assessment}

No formal in-depth critical appraisal was made of studies subsequent to their inclusion in the systematic map because the scope of the topic and the highly heterogeneous nature of the studies made this challenging. However, meta-data on aspects of study setting and design were extracted from included studies to provide a very basic 


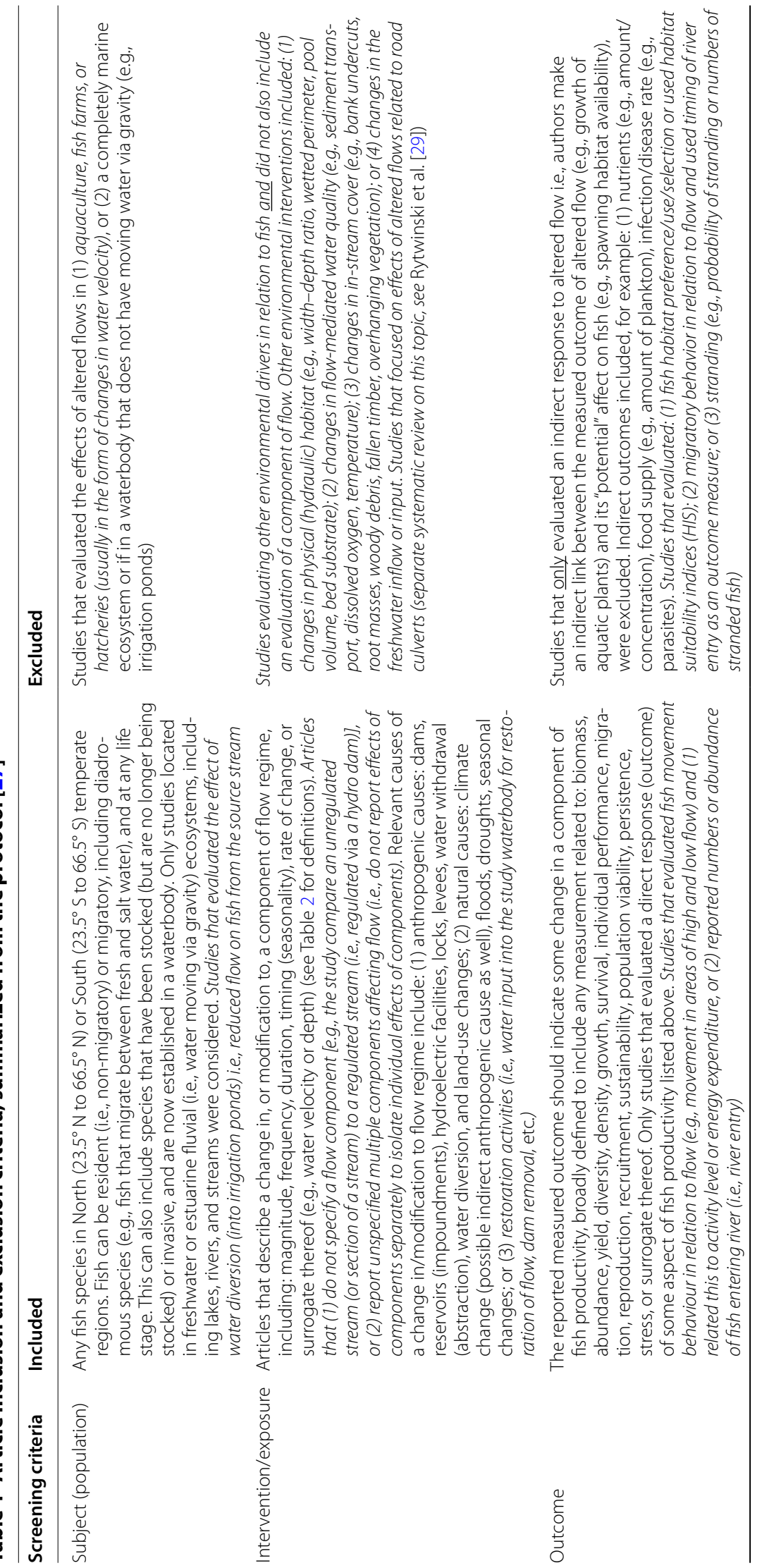




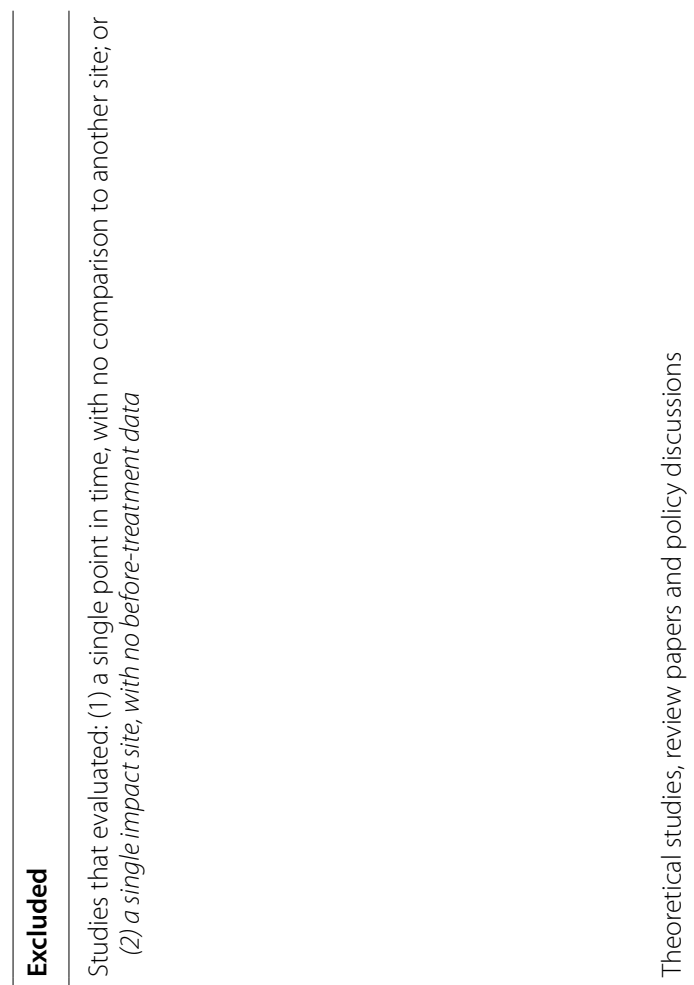

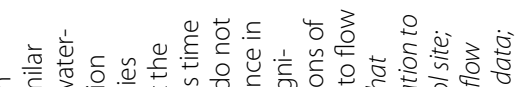

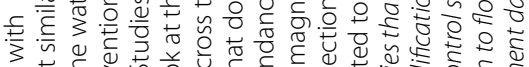

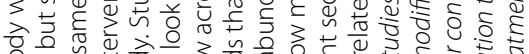

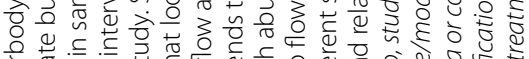

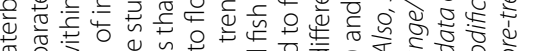

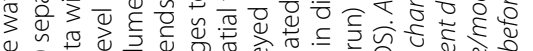

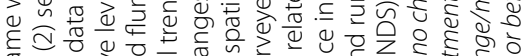

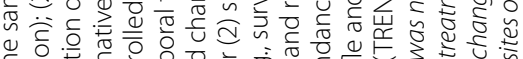
至.

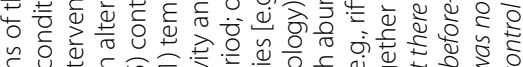

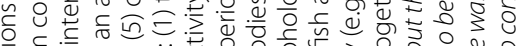

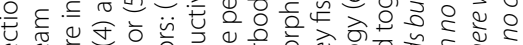
心

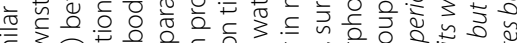
है

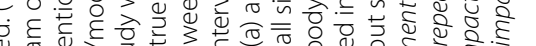
ه্

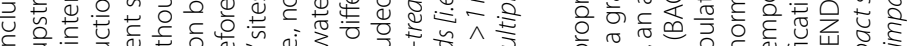

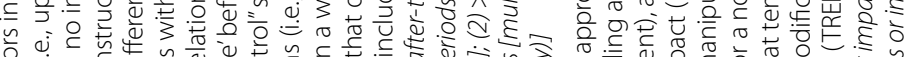

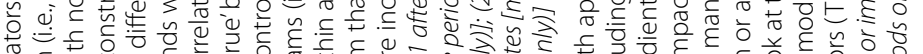

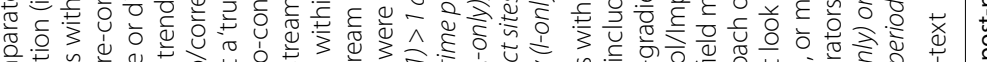
हैं

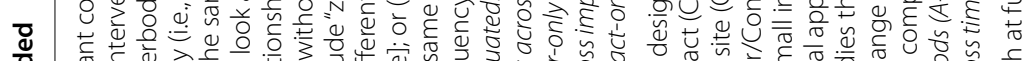

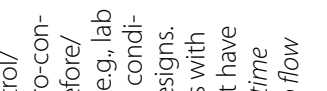

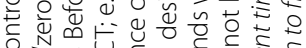

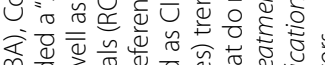

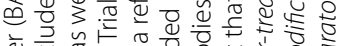

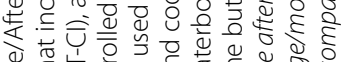

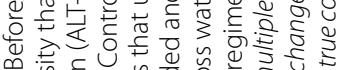
D. 产.

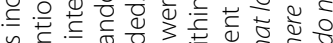

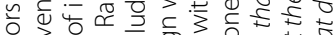
눙

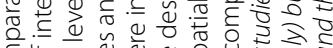

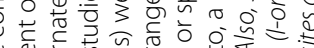


overview of the robustness and relevance of the evidence (i.e., internal validity). The primary purpose of extracting this meta-data was to aid future study validity assessments and synthesis of studies on sub-topics of interest identified from our systematic map exercise.

Study validity assessments were based on a modified list of variables used by Haddaway et al. [30] and combined with topic specific quality measures used by Cresswell et al. [31]. Terms including 'yes', 'partially', 'not at all', or 'unclear' were applied to each study based on study design (i.e., type of comparator), sample-selection methods, and other sources of bias as outlined below. Reviewers did not critically appraise studies for which they were an author. No studies were excluded from the database based on the study validity assessment criteria.

$\underline{\text { Yes }}$

Study design: Before/After/Control/Impact design (BACI) or Randomised controlled trial (RCT) (e.g., lab or small field manipulations).

Sample-selection methods: Randomised selection procedures of any form or studies that deliberately spread samples evenly across clear potential confounders.

Other sources of bias: No evidence of bias.

\section{$\underline{\text { Partially }}$}

Study design: Studies with one comparator i.e., Before/ After (BA), Control/Impact (CI) designs including a gradient of intervention intensity that included a "zerocontrol" site (CI-gradient) or incomplete BACI (INCOM$\mathrm{BACI}$ ) designs (i.e., data is missing for one component of the BACI design), or an alternate level of intervention (ALT-CI).

Sample-selection methods: Studies that did not state they used a form of randomised selection procedure but implied random or blocked designs.

Other sources of bias: Potential confounder, including, for example: (1) clear differences in environmental conditions or other factors that differ between intervention and comparator sites and/or times, that occur after sample selection and/or study initiation (e.g., unplanned human alterations, floods, droughts), or (2) substantial spatial separation between intervention and control sites.

\section{Not at all}

Study design: Studies that do not have true comparators but use temporal or spatial (within or across waterbodies) trends with a change in, or modification to, a component of flow regime (TRENDS), or that look at multiple aftertreatment time periods (A-only) or impact sites (I-only) but there was no change/modification to flow across the time periods or impact sites.
Sample-selection methods: Studies that stated purposive selection or those that were clearly purposive (i.e., no replication).

Other sources of bias: Clear confounder (bias).

\section{Unclear}

If information on any variable (i.e., study design, sample-selection methods, other sources of bias) was completely absent or could not be clearly determined. Note, an N/A term was applied for an individual-based study with a single sampling location (for sample-selection methods).

\section{Additional study validity assessment considerations}

We could not assess studies for their degree of true replication using a single quality measure because the levels of replication were not comparable across the diversity of fish productivity outcomes evaluated in relation to flow alteration effects. For example, the level of replication at which the intervention was administered/the exposure experienced could be at the level of: (1) individuals (e.g., metrics related to growth and performance); (2) spatial units (e.g., productivity metrics measured in entire waterbodies or in reaches/sections of a waterbody); or (3) temporal periods (e.g., productivity metrics measured at different time periods before and after the intervention was administered/the exposure experienced in a single waterbody). However, we did attempt to capture some information on replication in the form of collecting: (1) the unit of analysis (i.e., spatial, temporal, spatial + temporal, or individual fish); (2) a free form description of the unit of analysis (sample size used by authors); and (3) type of replication(s) [i.e., likely true spatial replication, clearly pseudoreplicated, within year, between year, unclear, number of fish, or none (if no true comparator: TRENDS, ALT-CI, A-only, or I-only study designs)] (see Additional file 3 for further details).

\section{Data coding strategy}

Following full-text screening of articles by the review team, relevant studies were extracted from the included articles i.e., when multiple studies were reported within one article they were entered as independent lines in the database. Here, we define a study to be an experiment or observation that was undertaken over a specific time period at a particular site reported as separate: (1) waterbodies that were not treated as replicates or used for spatial trend analysis within the article, or (2) laboratory experiments. Attempts were made to identify supplementary articles (i.e., articles that reported data that could also be found elsewhere or contained portions of information that could be used in combination with another more complete source), and combine them 
with the most comprehensive article (i.e., primary study source) during data extraction.

In developing the map data extraction form and codebook, the following key variables of interest were identified through scoping activities and discussion with the advisory team: (1) bibliographic information; (2) study location and details (e.g., geographic location, waterbody name and type, etc.); (3) broad objectives of the study; (4) study design and length; (5) intervention/exposure type (see Table 2 for definitions); (6) cause of intervention; (7) comparator type; (8) outcome type; (9) sampling method(s); (10) species (or species groups) (common and Latin names crosschecked with FishBase [32] or Eschemeyer's Catalog of Fishes [33]) and life stage(s) studied; and (11) the study validity assessment decisions on study design, sample selection, other sources of bias, and replication. Coding options within these key variables were then compiled in a partly iterative process, expanding the range of options as they were encountered during scoping and extraction.

To ensure that information for both coding and study validity assessments were being extracted in a consistent and repeatable manner, two reviewers (TR and $\mathrm{MH}$ ) piloted the extraction form by coding and assessing information from 15 of the same articles at the beginning of the process. Any disagreements were discussed and additional, more detailed guidance was added to the extraction codebook to improve clarity. Coding and study validity assessments then proceeded with one reviewer $(\mathrm{MH})$ and any queries were discussed with a second reviewer (TR) and a consensus decision made. If a decision for a given query could not be made by $\mathrm{MH}$ and TR, uncertainties were discussed and reconciled with the broader research team, and refinements to coding and validity assessments were made to the extraction codebook when necessary. The finalised extraction form and codebook for the map is shown in Additional file 4.

\section{Data mapping method}

A systematic map database was developed to describe the existing literature base on the effects of flow-regime changes on fish productivity in freshwater and estuarine fluvial environments (see Additional file 4). The searchable and accessible database was created in Microsoft Excel and provides the quantity and key characteristics of the research on this topic, detailing location, methodology, types and causes of altered flow regimes, fish productivity outcomes, and target taxonomic groups. The distribution and frequency of the evidence base was also compiled into a structured heatmap showing linkages between examined effects of flow-regime changes (rows) and fish productivity outcomes (columns). As studies within individual articles can examine links between more than one intervention and outcome type, individual studies were mapped to more than one cell when applicable (i.e., referred to as cases; see the "Mapping the quantity and quality of studies relevant to the question" section below for further details). Note, the systematic map does not quantify or validate direction of effects for fish outcomes examined but rather aims to describe the distribution of research effort. Specifically, the systematic map database and heatmap were used to identify possible

Table 2 Relevant intervention/exposure types assessed along with definitions

\begin{tabular}{|c|c|}
\hline $\begin{array}{l}\text { Intervention/ } \\
\text { exposure } \\
\text { type }\end{array}$ & Definition \\
\hline Magnitude & $\begin{array}{l}\left.\text { A change in the amount of water moving past a fixed location per unit time (e.g., } \mathrm{m}^{3} / \mathrm{s}\right) \text { : (1) peak flow (reported as alterations in } \\
\text { flood, peak, or high flow); (2) base flow (reported as alteration in base flow, low flow or drought conditions); ( } 3 \text { ) average discharge } \\
\text { (reported as alteration in total flow or mean flow); and (4) short-term variation (reported as a change in magnitude that occurred } \\
\text { over a period of hours or less than } 1 \text { day) }\end{array}$ \\
\hline Frequency & $\begin{array}{l}\text { The number of flow occurrences during a specified time period, where the magnitude of flow is either above or below a given thresh- } \\
\text { old. Frequency could be defined as the count or average of high or low flows per time period (e.g., the number of high pulses that } \\
\text { are three times the median daily flow per year, or the number of low flows where flow is below the } 25 \text { th percentile per season), or as } \\
\text { the probability of occurrence of a flow (e.g., the probability of a 100-year flood) }\end{array}$ \\
\hline Duration & $\begin{array}{l}\text { Period of time associated with a specific flow condition. Duration could be defined relative to a particular flow event (e.g., a floodplain } \\
\text { may be inundated for a specific number of days by a 10-year flood), or as a composite expressed over a specified time period (e.g., } \\
\text { the number of days in a year when flow exceeds some value). Antecedent flow, defined as the measure of time since a specific flow } \\
\text { level, was also included in the context of the number of dry days (form of duration of low flow) }\end{array}$ \\
\hline Timing & Timing, seasonality, or predictability of flows of defined magnitude (referring to the regularity with which they occur) \\
\hline Rate of change & Rate of change, refers to how quickly flow changes from one magnitude to another \\
\hline Surrogate & Surrogate of flow alteration e.g., water depth, flow stage (water level above an arbitrary point), water velocity, water area \\
\hline Unspecified & $\begin{array}{l}\text { An unspecified component of flow i.e., the study does not specify a flow component. For example, (1) the study compares an } \\
\text { unregulated stream (or section of a stream) to a regulated stream (i.e., regulated via a hydro dam) but does not include an actual } \\
\text { component of flow as outlined above); or (2) reports unspecified multiple components affecting flow (i.e., do not report effects of } \\
\text { components separately to isolate individual effects of components) }\end{array}$ \\
\hline
\end{tabular}


knowledge gaps (i.e., subtopics requiring further primary research) and knowledge clusters (i.e., subtopics that are sufficiently covered by existing studies to allow full systematic reviewing).

\section{Results}

\section{Literature searches and screening}

Our literature search yielded 25,464 hits from the six databases and Google Scholar (see Additional file 1). This resulted in 18,231 unique records after duplicate removal. At title and abstract screening, 15,793 articles were excluded, leaving 2438 for full-text screening (Fig. 1). At full-text screening, 1204 articles were excluded, 26 articles were unobtainable due to either insufficient citation information provided within search hits, or they could not be located through internet, Carleton University library subscriptions, or inter-library loan sources (see Additional file 2), and one further article was removed as a missed duplicate. The majority of articles were excluded at full-text because of an irrelevant intervention (i.e., the article did not describe a change in, or modification to, a component of flow regime), outcome (i.e., article did not evaluate a direct response of some aspect of fish productivity), or population (i.e., article reported data for non-temperate fish, or fish related to altered flows in aquaculture, fish farms, or hatcheries). All articles excluded at full-text along with reasons for their exclusion can be found in Additional file 2. From the databases and Google Scholar, 1207 articles were included at full-text.

In addition, 218 relevant articles were included after full-text screening from specialist websites (79 articles), bibliographies of relevant reviews (131 articles from 297 reviews; see Additional file 5 for a list of reviews) and included articles (2), and other searches (6). Combining all relevant articles, a total of 1425 articles met our inclusion criteria after full-text screening (Fig. 1). Of these, 32 were considered supplemental (redundant) articles because they overlapped with other included articles providing only additional information (e.g., extra years of data, intervention information), 10 were missed duplicates, and a further 184 were excluded after closer evaluation because they did not meet our inclusion criteria (Fig. 1). A total of 1368 studies from 1199 articles were included in the final map (Fig. 1). Coded data for all included studies are included in Additional file 4. A ROSES reporting form is included in Additional file 6.

\section{Mapping the quantity and quality of studies relevant to the question}

The quantity and quality of the available evidence base on the effects of flow-regime changes on fish productivity in freshwater and estuarine fluvial environments is described narratively below at the level of study (not article; see definitions outlined in the "Data coding strategy" section above). When reporting the number of individual studies (out of 1368 studies) for a given description i.e., in-text descriptive statistic or within figure(s)/table(s), we use the term studies. However, in some descriptions, we included multiple counts within a given study (e.g., multiple study designs, or species evaluated). In such instances, the number of studies will exceed the total number of studies included (i.e., $>1368$ studies). We still refer to these as studies when speaking generally about descriptions (e.g., "Most studies were performed in North America..."; however, to distinguish these counts from individual study counts, we use the term cases when providing in-text descriptive statistics (e.g., "Of the 43 included countries, the most studied were USA (50\% of cases)...", and in figure/table captions/legends where applicable. Counts of cases are thus situationally defined, meaning the total number of cases is not similar for all descriptions.

\section{Studies per decade}

Study publication dates ranged from 1940 to 2017, with the majority published after the year 2000 (72\%). From 1940 to 1979 , grey literature made up a larger proportion of the total studies than in more recent years (Fig. 2).

\section{Study location}

Studies included in this systematic map spanned a range of North and South temperate regions (Fig. 3). Most studies were performed in North America, Oceania, and Europe, although there were clear gaps in geographic coverage for studies in Northern Africa, and parts of Western, Central and South Asia (Fig. 3). Of the 43 included countries, the most studied were USA $(50 \%$ of cases), Canada (11\% of cases), and Australia (7\% of cases) (Fig. 3), with the majority of studies conducted in states/provinces along the west coast of North America [i.e., California, Washington, Oregon (USA) and British Columbia (Canada)], and the southeastern coast of Australia (i.e., New South Wales) (Fig. 4). The majority of studies were field-based studies conducted in rivers $(79 \%$ of studies), with some in estuaries ( $4 \%$ of studies), reservoirs ( $3 \%$ of studies), lakes ( $1 \%$ of studies), and wetlands ( $<1 \%$ of studies), whereas the remaining were lab-based studies conducted in research facilities ( $6 \%$ of studies), mixed locations ( $6 \%$ of studies; e.g., lab + field-based locations, or different waterbody types), or the waterbody type was not reported ( $<1 \%$ of studies).

\section{Study design}

The vast majority of studies either used a temporal or spatial trend design (e.g., correlation) that lacked a 


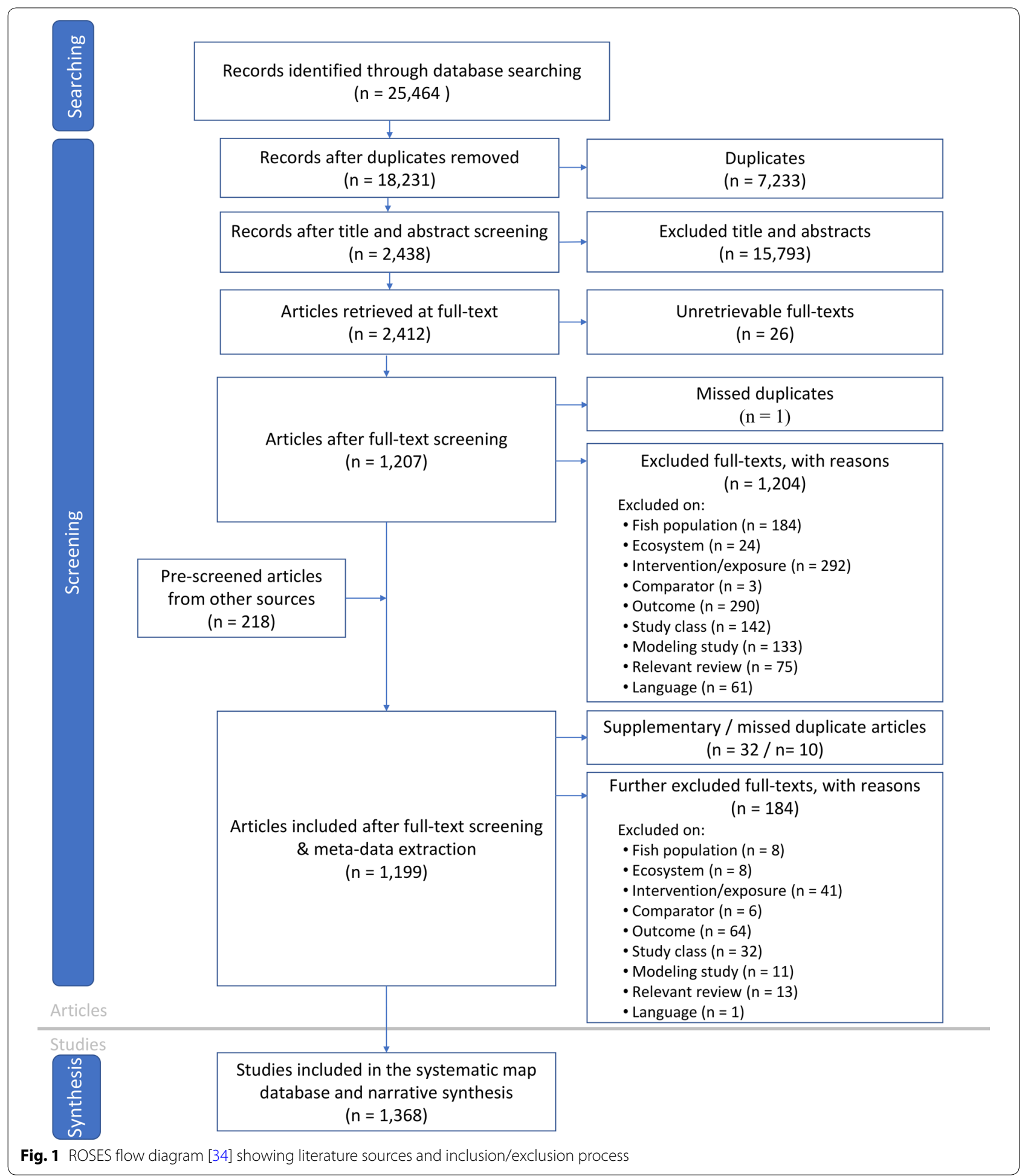

true comparator (64\% of cases) (Fig. 5). The next most common study design was a BA design (14\% of cases) which used a temporal intervention comparator (i.e., before intervention data within same waterbody) or an alternative level of intervention comparator [i.e., before intervention data within same waterbody but the intervention was not no intervention nor the base flow level (e.g., comparison of current discharge rate of a hydro 


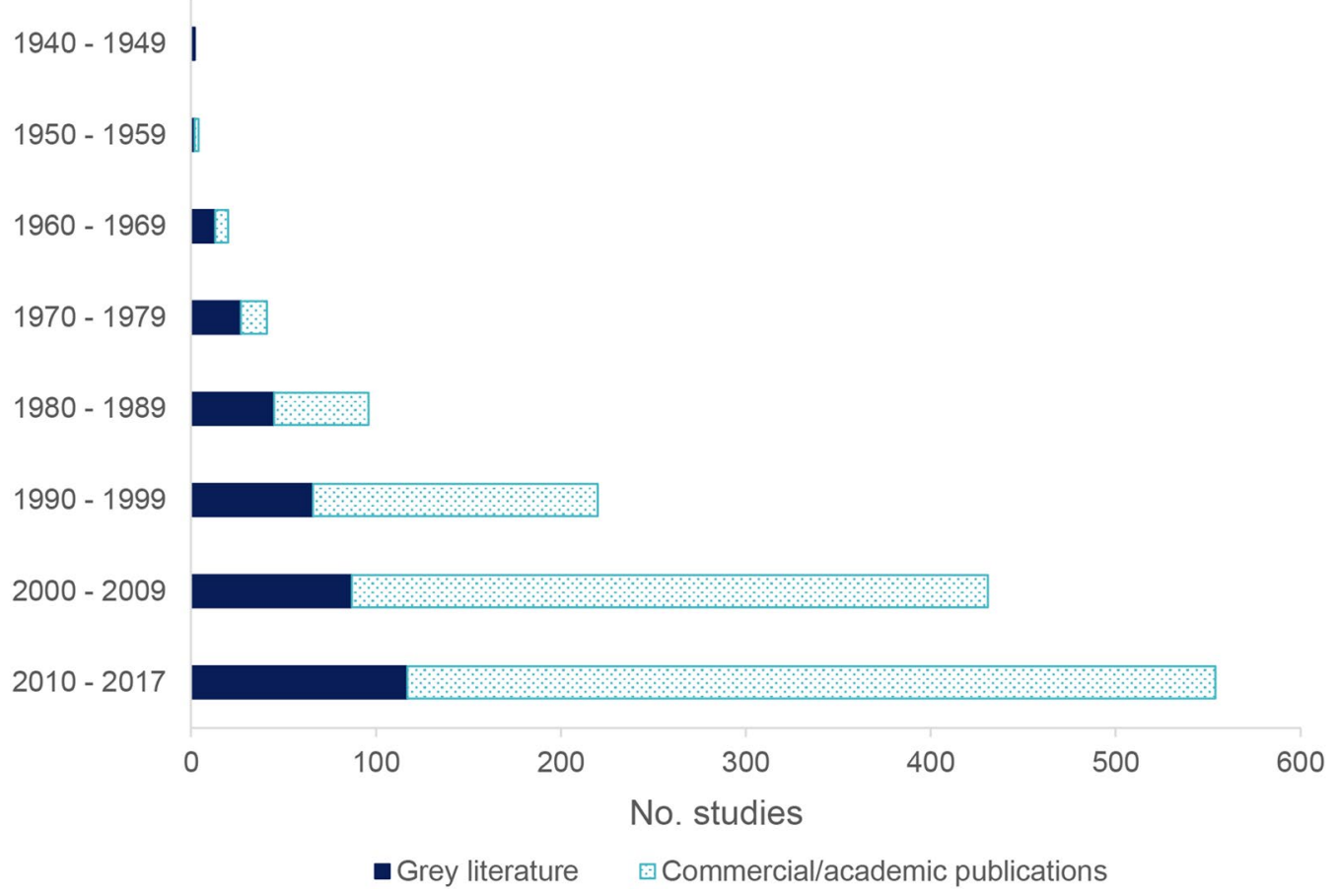

Fig. 2 Period of publication for the 1368 studies (from 1199 articles) in relation to source

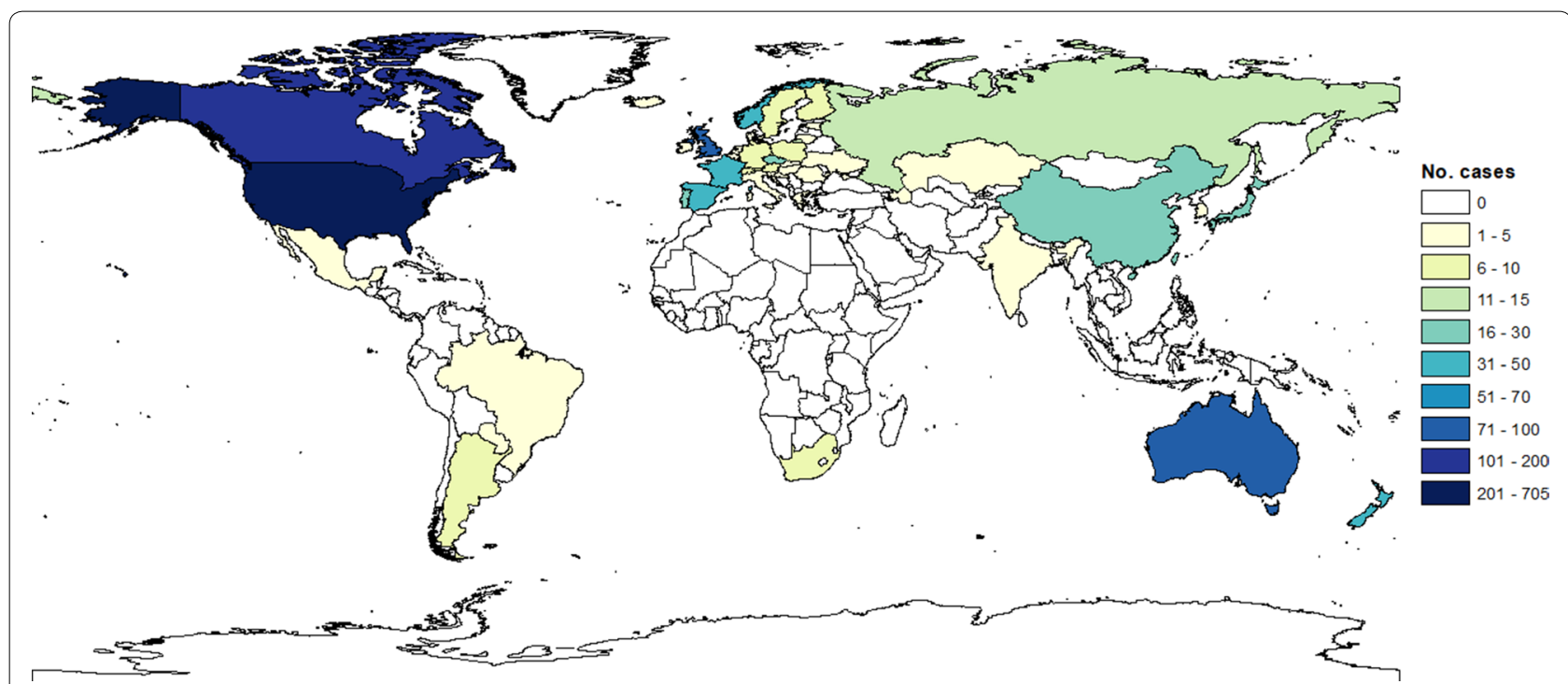

Fig. 3 Geographic distribution of evidence, displaying the number of cases per country. In this context, since some studies were undertaken across more than one country, counts were the number of cases (not studies). Note, most of the countries receiving ' 0 ' are in areas that are not temperate

dam vs. a faster discharge rate)] (Fig. 5). A number of studies employed a CI design ( $6 \%$ of cases) using a spatial comparator [i.e., similar sections of the same waterbody with no intervention or the base flow level (i.e., upstream or downstream condition), or separate but similar waterbodies with no intervention/base level (e.g., nearby unregulated waterbody)]. Some studies also used a gradient of intervention intensity design including "zero-control"-sites (CI-gradient; $4 \%$ of cases), with a similar proportion of comparator types as with CI design 


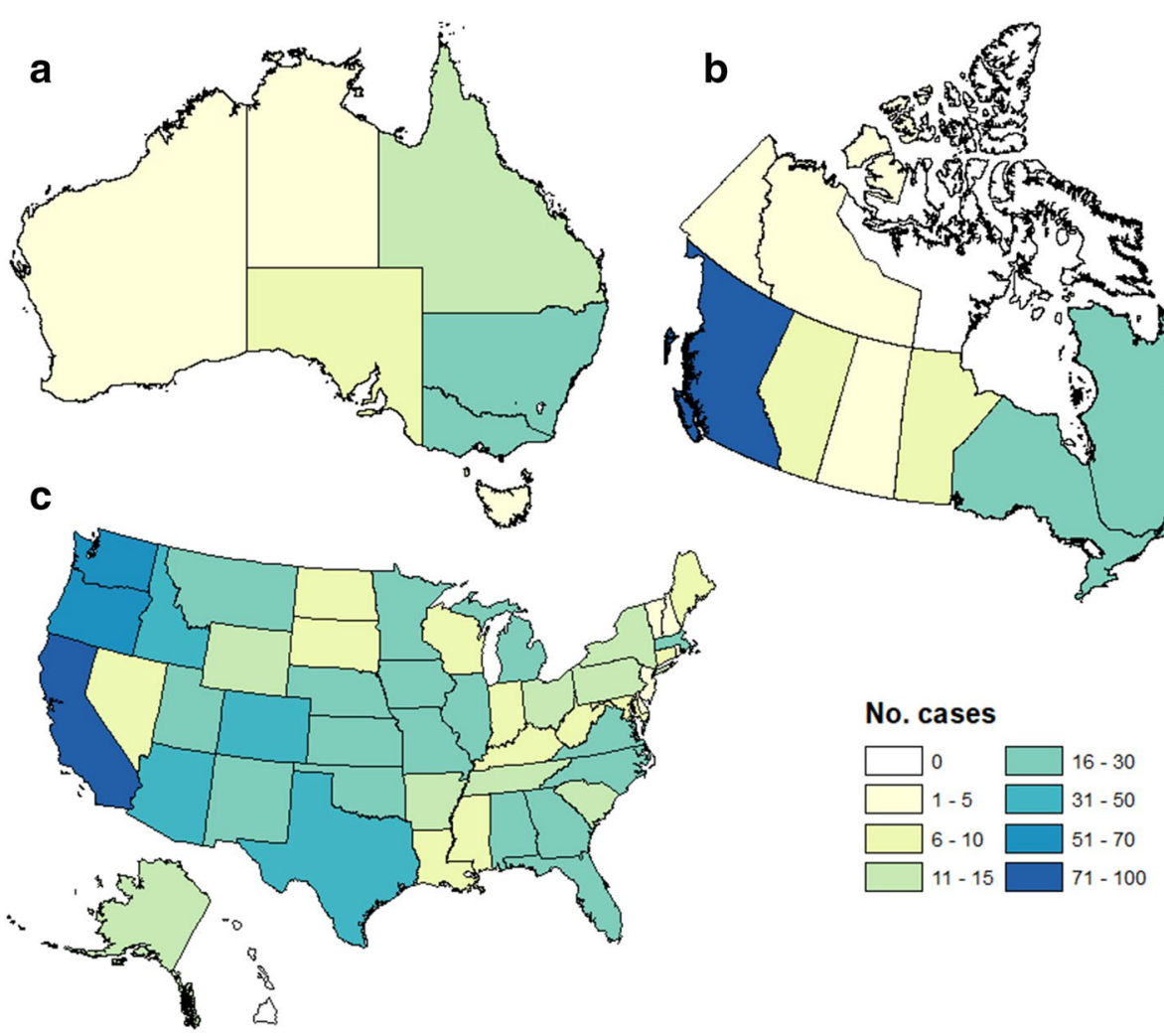

Fig. 4 Geographical distribution of evidence, displaying the number of cases per province/state, within the three most studied countries a Australia, b Canada, and c USA

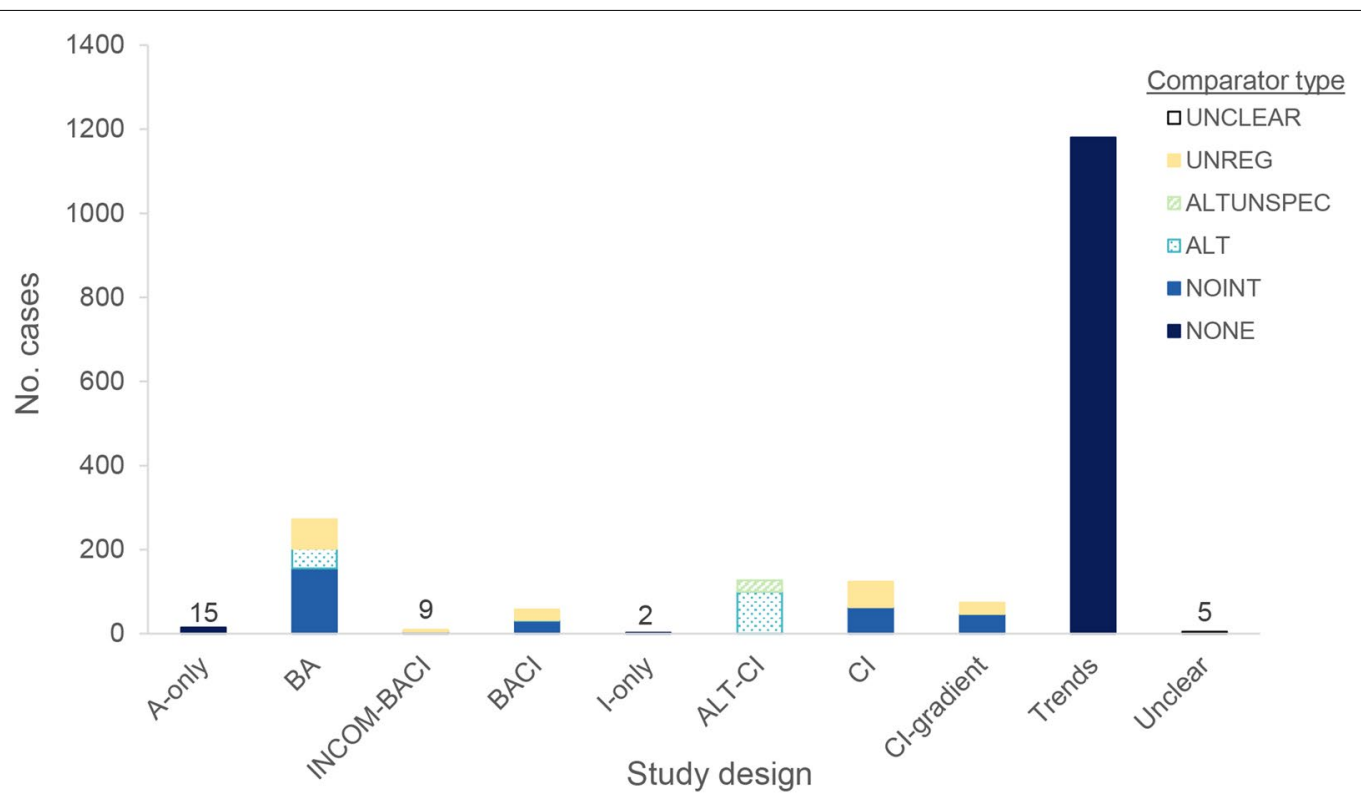

Fig. 5 The number of cases per study design in relation to the type of comparator used. Comparator type: NONE: no comparator; NOINT: no intervention (i.e., no change in a flow component or the base level of a flow component); ALT: alternative intervention; ALTUNSPEC: alternative intervention for studies that do not specify a particular component of flow; UNREG: an unregulated waterbody for studies that do not specify a particular component of flow; UNCLEAR: unclear comparator type. Codes for study designs are detailed in Table 1. Data labels are placed on study designs that accounted for $<1 \%$ of included cases 
studies, or an alternative level CI design (ALT-CI; 7\% of cases) using a comparator that was not no intervention or base flow level but a different flow condition (an isolated or unspecified component of flow) (Fig. 5). Relatively few studies used a BACI (both temporal and spatial comparators; $3 \%$ of cases), an incomplete BACI (either a temporal or spatial comparator; $<1 \%$ of cases), or multiple time periods after a change/modification of flow (A-only; $<1 \%$ of cases) or multiple impact sites (I-only) that had no comparators (Fig. 5).

Study duration (i.e., years for which outcome data were collected/evaluated) varied across studies included in the map (Fig. 6). Most of the studies reported outcome data for $\leq 4$ years ( $58 \%$ of studies), the majority of which were for 2 years. A number of studies either failed to report study duration (3\% of studies) or study length/dates were reported in some manner but were exceptionally unclear ( $2 \%$ of studies). Note, only study duration was captured here, not the interval for which collections/evaluations were taken.

\section{Study validity assessment}

Relatively few studies used both spatial and temporal comparators (i.e., BACI; 3\% of cases) or one comparator (i.e., BA, CI, CI-gradient, INCOM-BACI, ALT-CI; 31\% of cases); most used study designs with no true comparators (i.e., TRENDS, A-only, I-only; 65\% of cases) (Fig. 7). Close to one-third (31\%) of cases deployed some form of a randomised selection procedure or deliberately spread samples evenly across clear potential confounders, and over half (55\% of cases) reported no other evident sources of bias (e.g., unplanned human alterations, floods, droughts, or substantial spatial separation between impact and control sites) (Fig. 7). Overall, few cases (20\%) received a 'yes' or 'partially' for all criteria.

The most common unit of analysis for which the intervention was administered/the exposure experienced was at the level of temporal periods (47\% of cases), the majority of which were trends across time with no true before intervention time period(s) and therefore considered unreplicated (72\% of temporal cases; Fig. 8 ). When temporal comparators were used (i.e., BA designs), most were between year comparison (e.g., outcome means and variances were from averaging across before and after year time periods; sample size was the number of years for each group) versus within year (e.g., daily or monthly outcome averages, usually within a single season/year) ( $18 \%$ vs. $6 \%$ of cases, respectively). Studies used spatial units of analysis in $25 \%$ of cases, and most often without true comparators (i.e., spatial TRENDS, ALT-CI) (68\% of spatial cases; Fig. 8). More studies used true spatial replication (e.g., the level of replication was at the entire waterbody) rather than pseudoreplication [e.g., outcome means and variances were obtained from averaging across multiple (relatively) small areas in close proximity to each other within a single waterbody; see Additional file 3 for further details] ( $17 \%$ vs. $12 \%$ of cases, respectively; Fig. 8). When both spatial and temporal units

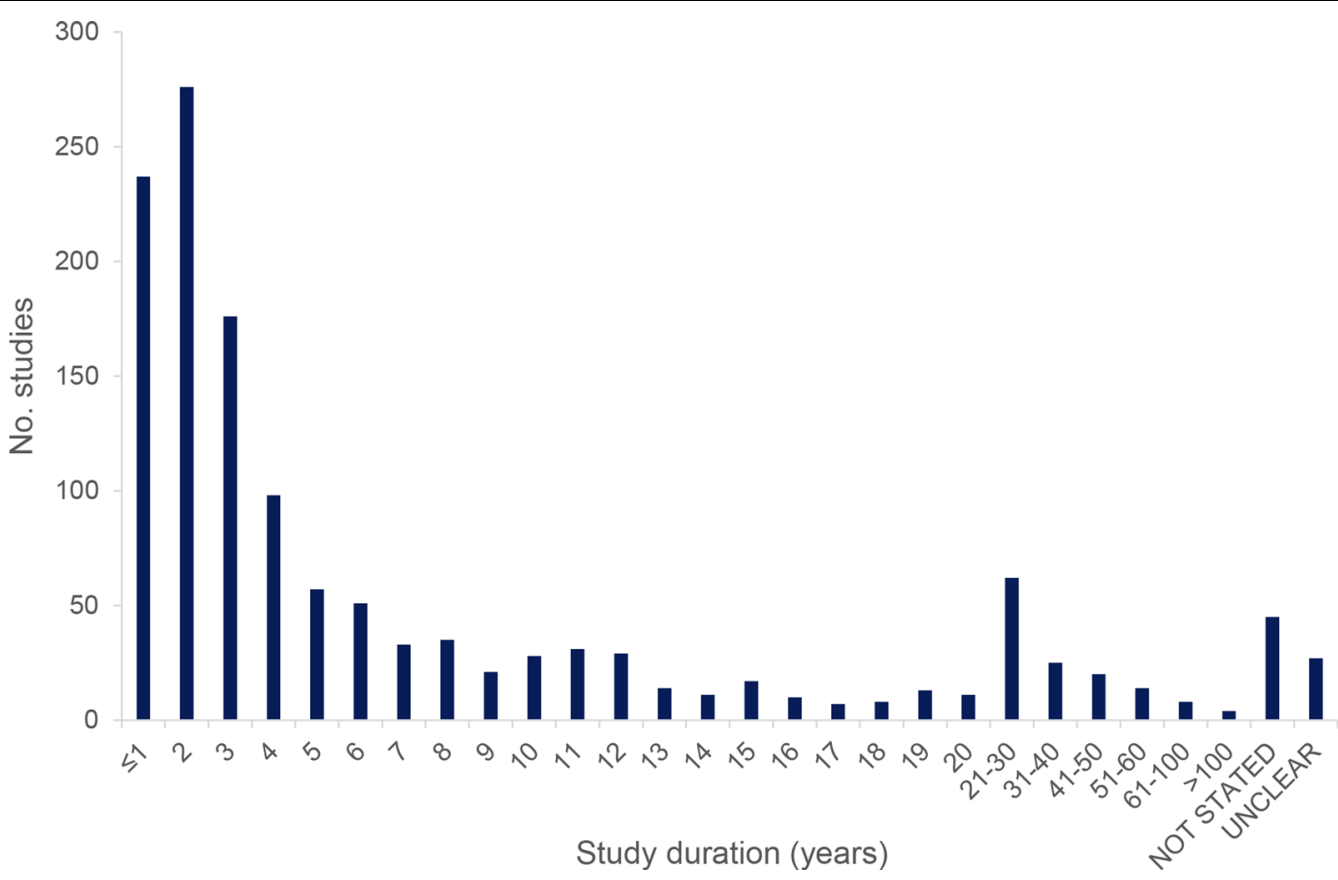

Fig. 6 The number of studies (out of 1368) in relation to study duration (i.e., years for which outcome data was collected/evaluated) 


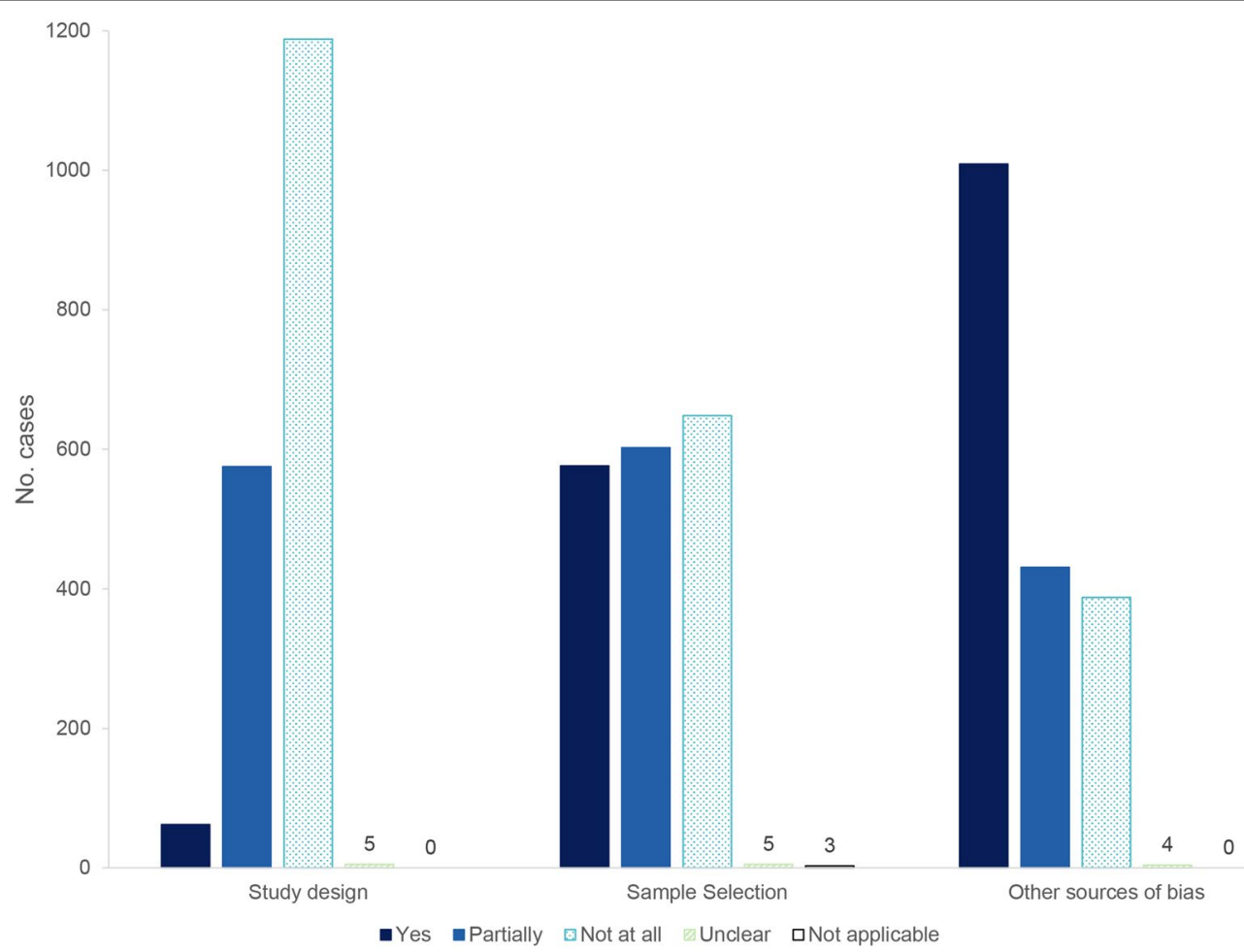

Fig. 7 Outcome of the study validity assessment

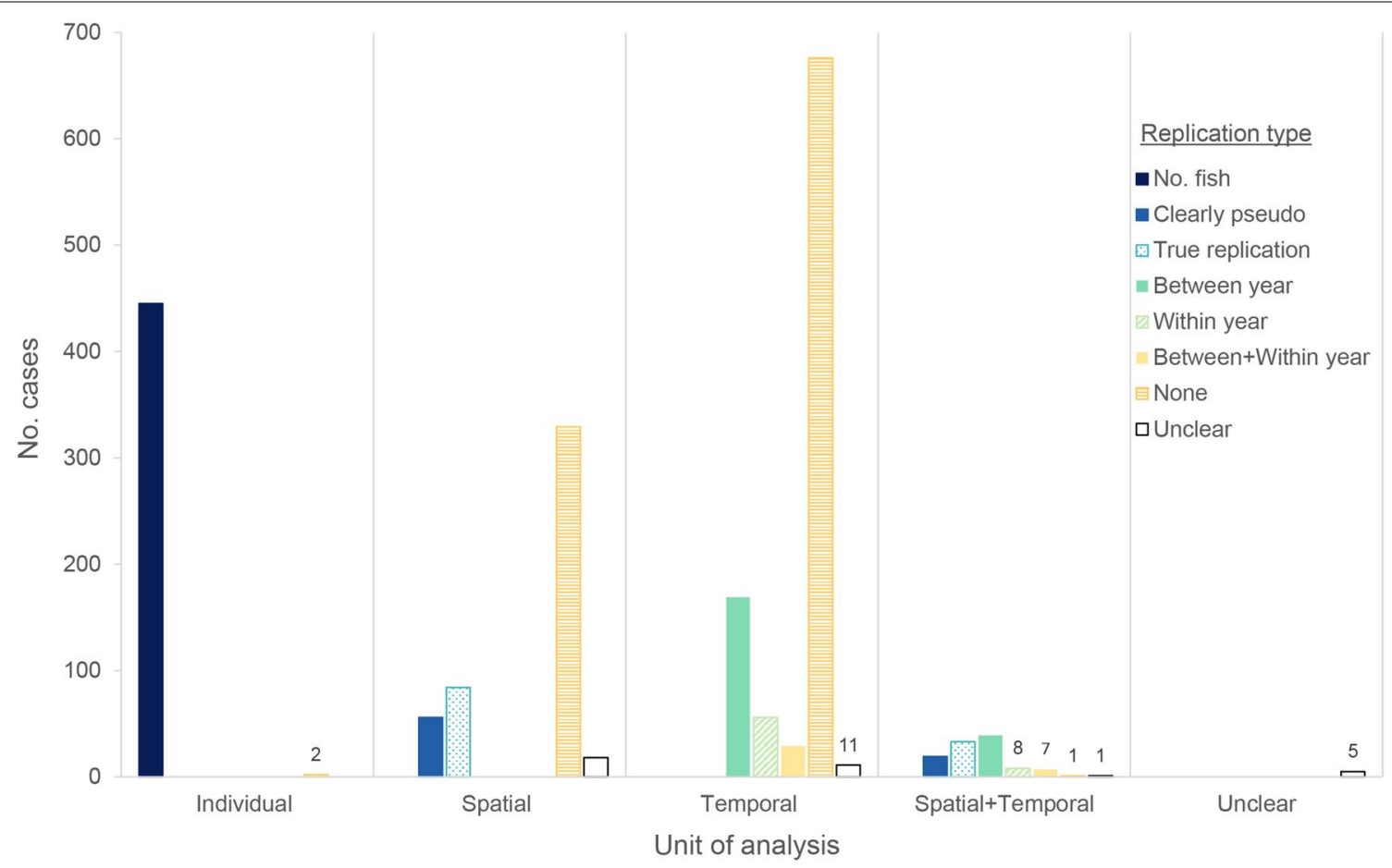

Fig. 8 The number of cases per unit of analysis in relation to the type of replication 
of analyses were used (i.e., BACI designs), most cases used true spatial and between year temporal replication (Fig. 8). A number of studies also used individual fish as the unit of analysis (e.g., when outcome metrics were related to growth and performance) (23\% of cases; Fig. 8 ).

\section{Population}

Studies that were included in the map investigated the effect of flow-regime changes on 2115 fish species from 787 genera and 195 families (see Additional file 7 for a list of associated synonyms of species names used in included studies). Salmonidae were the most common family studied including most frequently Oncorhynchus, Salmo, Salvelinus, Thymallus, and Prosopium (Fig. 9). Many studies also targeted fish from the Cyprinidae family, most often from genera Cyprinus, Notropis, Pimephales, Cyprinella, and Carassius (Fig. 9).

The vast majority of studies conducted species-specific investigations i.e., provided data for individual species rather than grouped/pooled species into broader categories [94\% of studies (1292/1368)]. Of those studies that conducted species-specific investigations, most targeted 1 species [ $48 \%$ of studies $(622 / 1292)$ ], but the number of focal species ranged from 1 to $913(8.24 \pm 0.809 \mathrm{SE})$. Of those studies that targeted a single focal species, most species were Atlantic Salmon (Salmo salar, 69/622 studies), Sea Trout (S. trutta morpha trutta, 69 studies), Chinook Salmon (Oncorhynchus tshawytscha, 53 studies), Rainbow Trout/Steelhead (O. mykiss, 30 studies), European Eel (Anguilla anguilla, 19 studies), and Brook Trout (Salvelinus fontinalis, 17 studies).

When reported, most studies were conducted on adult fish (378 cases), followed by juveniles (e.g., age 1+, smolts, 317 cases) and age 0 fish (e.g., fry, YOY, 228 cases) (Fig. 10).

\section{Causes of and changes in/modifications to flow regime (intervention/exposure types)}

A number of natural and anthropogenic causes of modification in flow regimes were described in the literature (Fig. 11). The most studied causes were natural (e.g., floods, droughts, seasonal changes, climate change), hydroelectric facilities, and dams with no hydroelectric facilities (Fig. 11). Natural and dam with no hydro causes were most frequently studied in USA, Canada, Australia, and the United Kingdom (UK), whereas changes in flow from hydroelectric facilities were examined most often in USA, Canada, Russia, and China (Fig. 12). There were also a number of studies that examined flow-regime changes due to multiple causes (e.g., land-use changes along with water extraction, hydroelectric facilities with naturally caused changes in flow regime) (Fig. 11), often in USA, Australia, and France (Fig. 12). Comparatively, few studies focused on causes related to experimental manipulations often conducted in a laboratory setting ('Other' causes in Fig. 11), water abstraction or diversions, restoration activities (e.g., dam removal, water input for restoration of flow) and land-use changes (e.g., highway construction, forest clear cutting). Additionally, there were many studies that did not provide clear information on the cause of altered flows (Fig. 11).

The majority of evidence was centered on evaluating changes in fish productivity due to changes in magnitude of flow caused by natural (e.g. flood, drought) and anthropogenic (e.g. dams, hydroelectric) agents (Fig. 11). Other commonly studied intervention types were surrogate measures of flow regime change [e.g., water depth, velocity, area, flow stage (water level above an arbitrary point)], and unspecified component(s) of flow regime, where for example, a study compared an unregulated stream (or section of a stream) to a regulated stream but did not include an actual component of flow such as magnitude or rate of change, or there were multiple components affecting flow (i.e., the study did not report effects of components separately to isolate individual effects of components) (Fig. 11). Relatively fewer studies focused on changes to (or manipulations of) flow duration, frequency, rate of change, or timing (Fig. 11).

\section{Measured outcomes}

Reported outcome measures were numerous and quite variable. As a result, responses were grouped into six broad outcome categories related to fish productivity: growth, survival, individual performance, migration, reproduction, and productivity (Table 3 ). Within each outcome category, metrics were grouped into more closely related outcome sub-categories (Table 3). Outcome metrics related most directly to fish productivity or production in general were the most frequently studied (59\% of cases), with the majority focusing on abundance and diversity sub-category metrics. There were also a number of studies that focused on metrics related to growth (e.g., changes in fish mass or length, somatic condition), migration (e.g., number of migrants, fish passage success), and reproduction (e.g., number of spawning adults, egg abundance, egg-to-fry survival) (Table 3 ). Comparatively, few studies focused on outcome metrics related to survival (e.g., beyond age 0 survival or mortality) and individual performance [e.g., swimming performance, activity level or measures of metabolic rate, sub-lethal stress indicators (e.g., vent rate, glutathione-Stransferase (GST) activity)] (Table 3). 


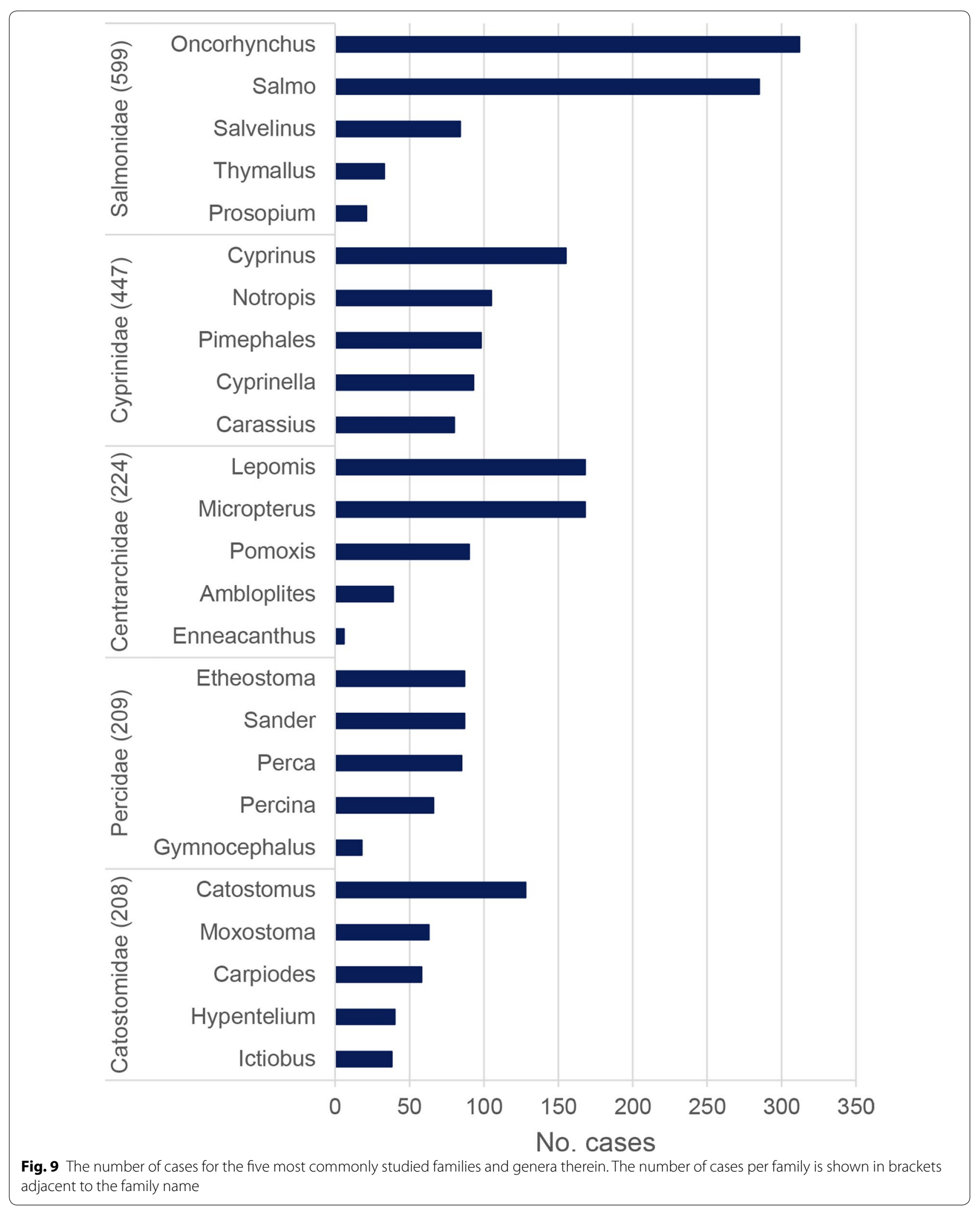




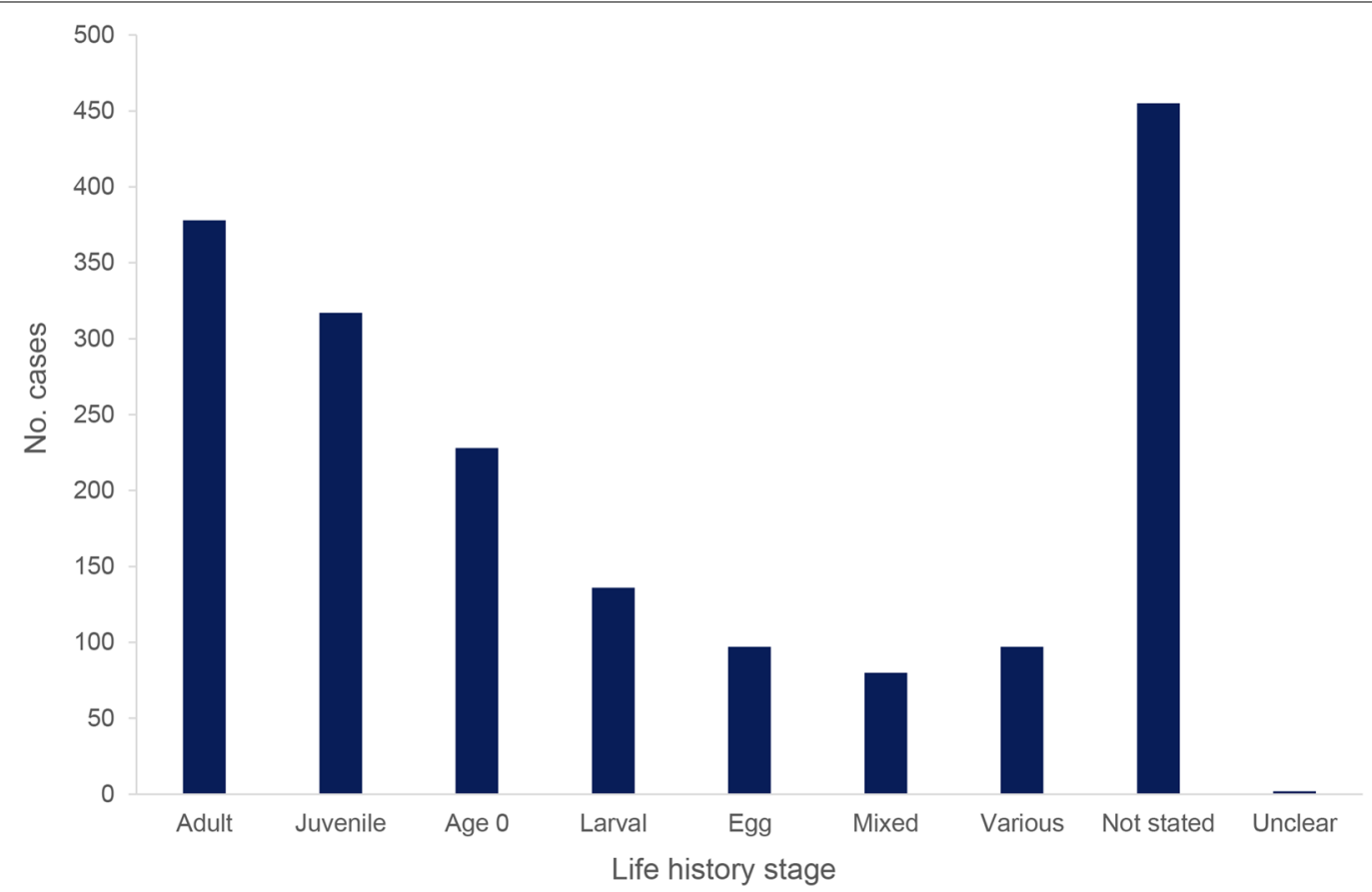

Fig. 10 The number of cases in relation to fish life history stage. Egg: eggs, nests/redds; Larval: larvae, alevins, free embryos; Age 0: fry, parr (0+), Age 0+, YOY; Juvenile: age 1+, parr (1+), juvenile, fingerling, smolt; Adult: adult, spawner, kelt; Mixed: assortment of life stages (combined); Various: $>2$ life stages reported separately for at least one outcome

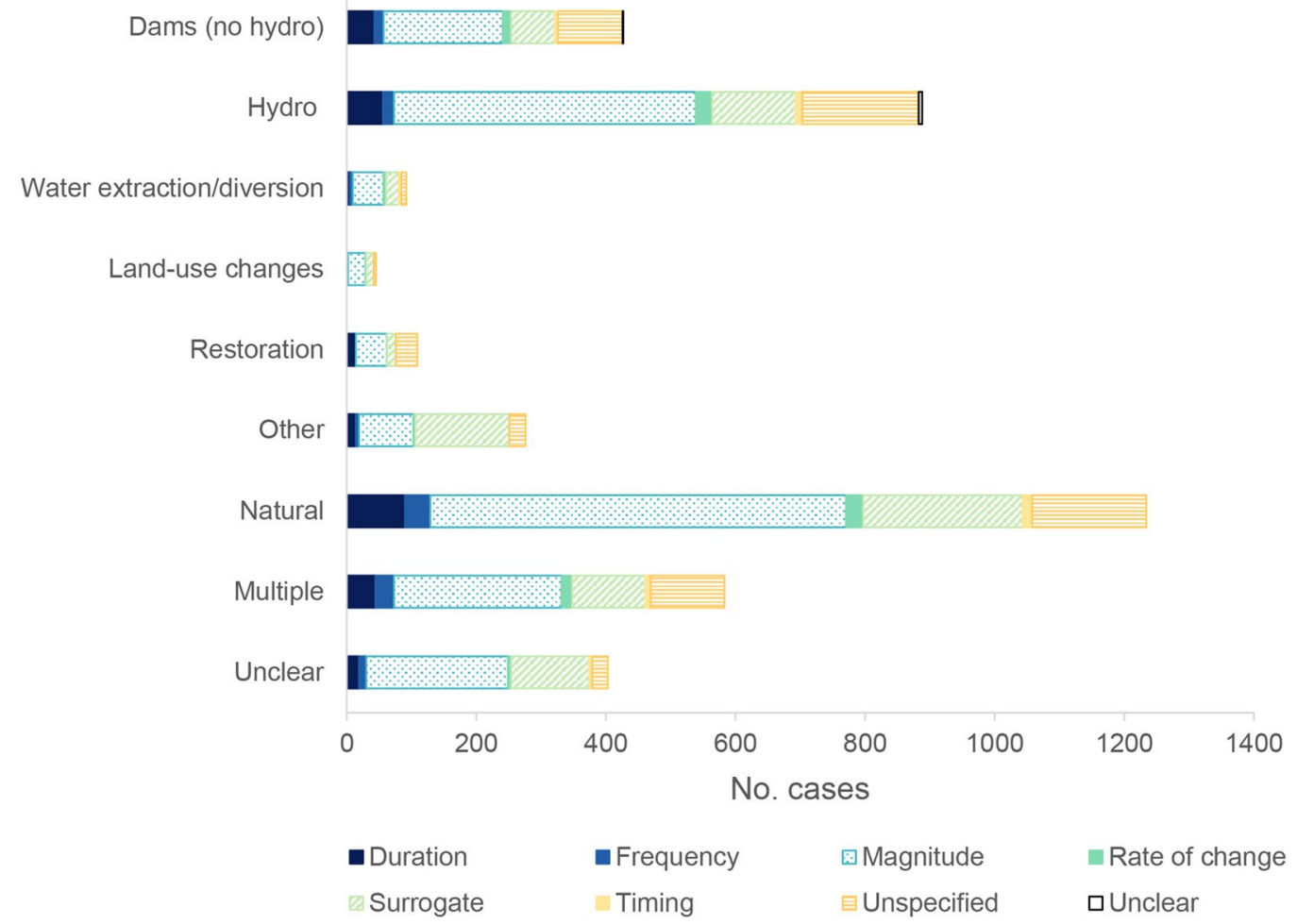

Fig. 11 The number of cases per cause of a change in/modification to flow regime in relation to intervention/exposure types. Other: experimental manipulations that were not related to any other cause of a change in/modification to flow regime 


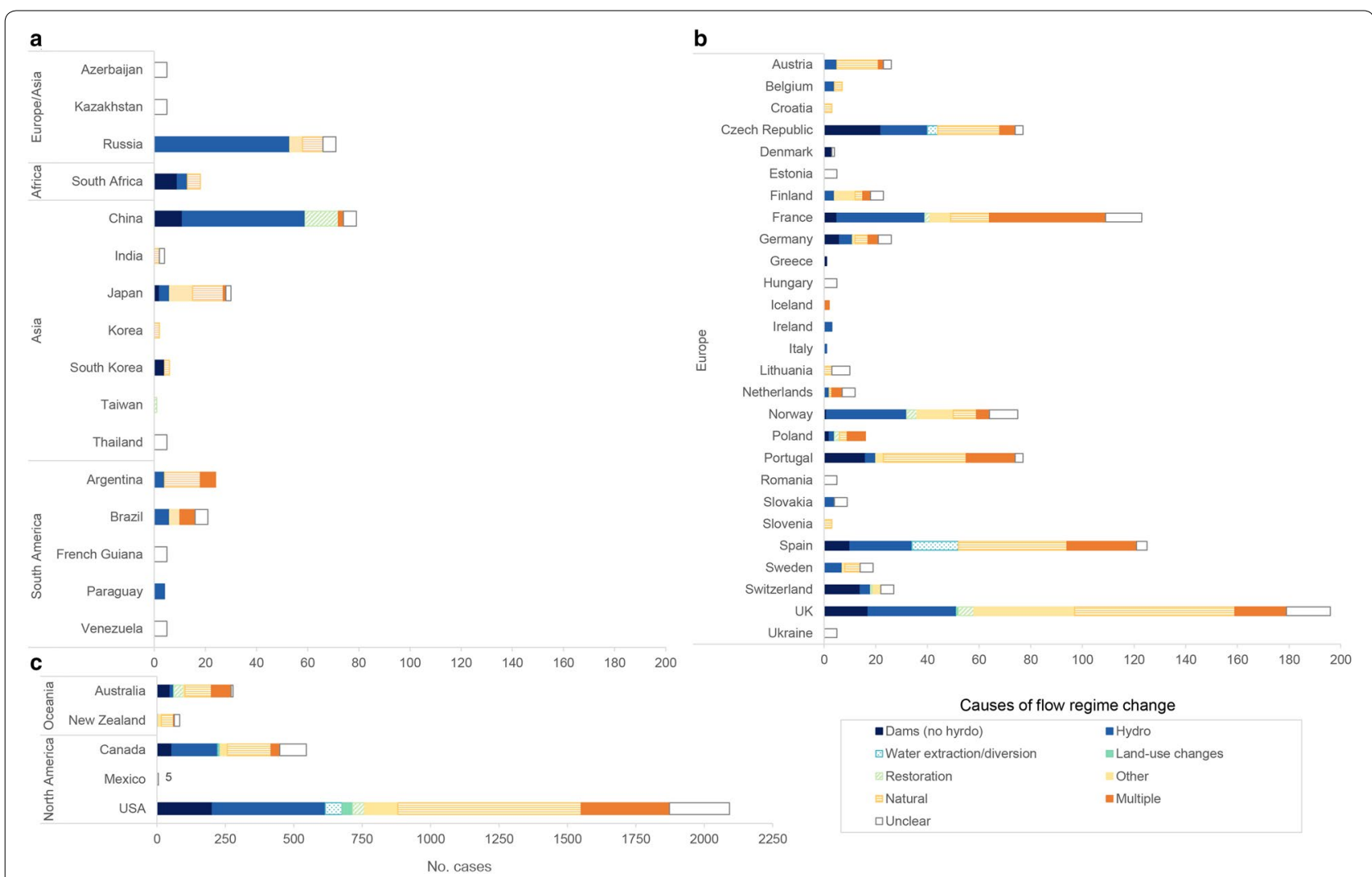

Fig. 12 The number of cases performed in different countries separated by the cause of a change in/modification to flow regime within a Europe/ Asia, Africa, Asia, and South America, b Europe, c North America and Oceania. Note, the $\mathrm{x}$-axis difference in scales between $(\mathbf{a}, \mathbf{b})$ and $(\mathbf{c})$

\section{Intersection of flow-regime changes and fish productivity outcomes}

Figures 13 and 14 present visual heatmaps of the distributions and frequencies of examined effects of flowregime changes (grouped by the cause of such change) on fish productivity outcomes. In this matrix of counts (cases), darker coloured cells indicate higher frequency of occurrences of evidence, while lighter colours show lower occurrences.

Focusing on dam (with no hydroelectric facilities) related changes in flow, most studies examined the effects of changes in magnitude and unspecified components of flow on fish productivity metrics, in particular abundance and diversity outcomes, with comparatively few exploring relationships between altered flows (any intervention types) and fish survival or performance outcomes (Fig. 13).

Of all causes of altered flows, hydroelectric related flow-regime changes appeared to have the largest distribution of studies across interventions and fish outcomes (Figs. 13 and 14). There were clear concentrations of evidence for alterations in magnitude and fish productivity outcomes (i.e., abundance, biomass, diversity, age-class structure), migration (i.e., number of migrants, fish passage success, speed), and growth (i.e., mass) (Fig. 13). Natural causes of changes in flow showed similar patterns in study focus as hydroelectric causes, but had higher occurrence of evidence for these concentrations (Fig. 14).

Studies examining changes in flow regime due to multiple causes primarily focused on relationships between changes in magnitude, surrogate measures, and unspecified components of flow, and fish abundance and diversity metrics (Fig. 14).

Overall relatively few studies focused on examining changes in fish productivity due to other forms of experimental flow manipulations (e.g., most often studies conducted in a laboratory setting) (Fig. 14). However, there was a high occurrence of studies that investigated changes in surrogate measures, frequently water velocity and/ or depth, and outcomes measured at the individual fish level such as growth and performance metrics, in particular, swimming performance (Fig. 14). Studies focusing on effects of alterations of flow regime on fish outcomes due to water abstraction or diversions, restoration activities and land-use changes were less studied (Fig. 13). 
Table 3 Outcome categories and sub-categories used to measure a change in fish productivity

\begin{tabular}{|c|c|c|}
\hline \multirow{2}{*}{$\begin{array}{l}\text { Outcome categories } \\
\text { Growth (576) }\end{array}$} & \multicolumn{2}{|c|}{ Outcome sub-categories and definitions } \\
\hline & Mass (414) & Mass, length; by age class \\
\hline & Condition (125) & Condition (somatic) \\
\hline & Foraging (37) & Foraging success e.g., mean energy intake, \% stomach fullness \\
\hline \multirow[t]{2}{*}{ Survival (159) } & Survival (95) & Survival (beyond age 0) \\
\hline & Mortality (64) & Mortality (beyond age 0) \\
\hline \multirow[t]{3}{*}{ Performance (individual) (114) } & Stress (16) & $\begin{array}{l}\text { Sub-lethal stress (only if direct response to altered flow) e.g., vent rate/respiration } \\
\text { frequency, glutathione-S-transferase activity, catalase activity, activity of 7-ethoxyre- } \\
\text { sorufin O-deethylase, cortisol/glucose levels }\end{array}$ \\
\hline & Energy (48) & $\begin{array}{l}\text { Activity level, energy expenditure (fish behaviour-movement in high/low flow), costs } \\
\text { of swimming, any measure of metabolic rate (e.g., rate of energy expenditure per } \\
\text { unit time) or indicator thereof in order to include changes in metabolism (e.g., field } \\
\text { metabolism measured in carbon isotope 13) }\end{array}$ \\
\hline & Swimming (50) & $\begin{array}{l}\text { Swimming performance including ability to maintain position in different flows e.g., } \\
\text { magnitude of thrust, swim speed/velocity }\end{array}$ \\
\hline \multirow[t]{5}{*}{ Migration (474) } & Passage (101) & $\begin{array}{l}\text { Metrics related to fish passage or success, including probability of migration over a } \\
\text { dam or through migration route }\end{array}$ \\
\hline & Passage (survival) (12) & Studies that consider loss or survival during passage \\
\hline & Speed (83) & Migration speed, net ground speed \\
\hline & Abundance (211) & $\begin{array}{l}\text { Abundance or numbers of fish e.g., number of migrants (river entry), or number of } \\
\text { successful migrants }\end{array}$ \\
\hline & Abundance (escapement) (67) & $\begin{array}{l}\text { Biological definition of escapement i.e., number of fish in a run/migration that are } \\
\text { able to return to the spawning ground or other important habitat, that do not get } \\
\text { stopped/removed by any barriers during migration and are available to support the } \\
\text { population into future years }\end{array}$ \\
\hline \multirow[t]{5}{*}{ Reproduction (332) } & Maturation (13) & Adult maturation success \\
\hline & Survival (84) & Redds/nest, egg, larval, fry, age 0, YOY survival (inclusive) \\
\hline & Spawning (106) & $\begin{array}{l}\text { Spawning events e.g., number of spawning days, spawning periods, number of } \\
\text { spawning adults }\end{array}$ \\
\hline & Spawning (abundance) (96) & $\begin{array}{l}\text { Egg abundance, number of eggs deposited/spawned, egg density during spawning } \\
\text { (may include other age groups if directly linked to spawning) }\end{array}$ \\
\hline & Fecundity (33) & Metrics related to fecundity \\
\hline \multirow[t]{8}{*}{ Productivity (2402) } & Biomass (239) & Metrics related to biomass, yield \\
\hline & Abundance (1031) & $\begin{array}{l}\text { Abundance, density, CPUE (total numbers, of just } 1 \text { age class), presence/absence, } \\
\text { number of eggs when eggs are considered an age class and not part of a spawning } \\
\text { event }\end{array}$ \\
\hline & Abundance (escapement) (1) & $\begin{array}{l}\text { Fisheries definition of escapement i.e., the number of fish in a fishery that manage to } \\
\text { get out of the fishery (leave the lake and are unavailable to fishers) }\end{array}$ \\
\hline & Diversity (567) & Diversity, richness, composition \\
\hline & Structure (266) & $\begin{array}{l}\text { Age class structure of population (numbers for }>1 \text { age class) or length-frequency } \\
\text { distribution i.e., replication is not individuals }\end{array}$ \\
\hline & Population viability (22) & $\begin{array}{l}\text { Population viability, persistence, sustainability, genetic diversity (within species), } \\
\text { number of hybrids (if linked to genetic diversity, otherwise hybrids are included like } \\
\text { any other fish under abundance) }\end{array}$ \\
\hline & Recruitment (197) & Recruitment metrics e.g., density of fry recruiting into adult population \\
\hline & Other (79) & E.g., production, turn-over \\
\hline
\end{tabular}

The number of cases per category and sub-category are shown in brackets

\section{Limitations of the map}

\section{Limitations of the map due to the search strategy}

The search strategy used to generate this map was designed to capture the breadth of relevant topics; however, the diversity of terminology used for measuring changes in flow regime as well as fish productivity outcomes was such that this review may not be considered completely exhaustive (i.e., some terms may have been missed that could result in bias in our evidence map). For example, in general, there were relatively few studies evaluating effects of changes in duration, frequency, rate of change or timing on any outcome 


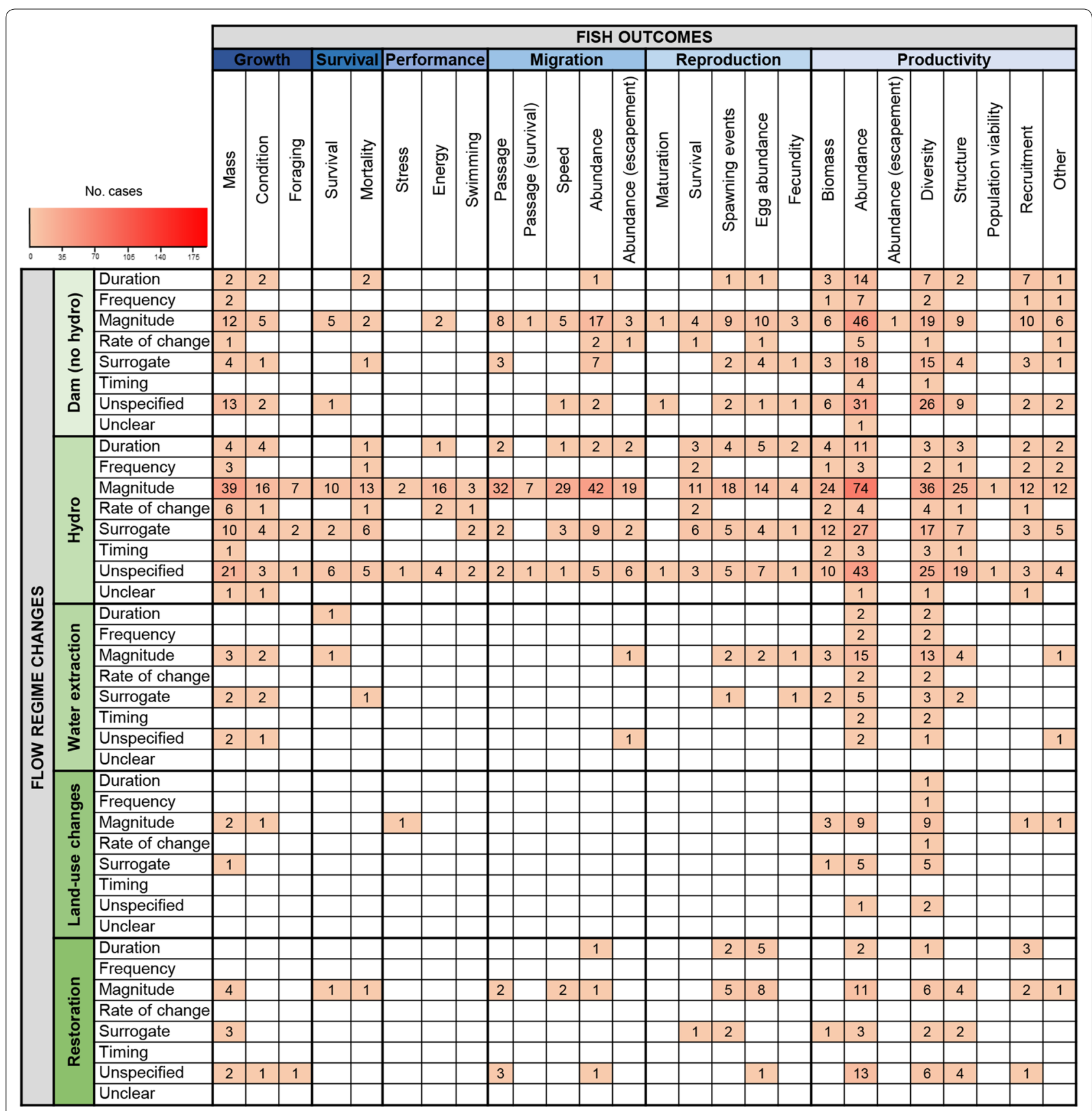

Fig. 13 Distribution and frequency of cases examining effects of flow-regime changes (grouped by the cause of such change; 5 of the 9 possible causes-see Fig. 14 for remaining causes) on fish productivity outcome categories and sub-categories

category. In our search string, we used relatively few intervention/exposure terms (i.e., Flow* OR Discharg*). However, we did carefully scope our search string for intervention terms by including terms such as: Regime\$, Magnitude, Ramp*, Frequenc*, Duration\$, Flash*, Peak*. Although these inclusions of terms resulted in more hits, more often than not, these articles were irrelevant. When articles were relevant, the included terms were found to be redundant with the terms flow and/or discharge that were also used in the same article's title, abstract, and/or key words.

Additionally, there were relatively few studies captured in the map on restoration, land-use change, or water extraction/diversion. Two of these relevant causes of flow 


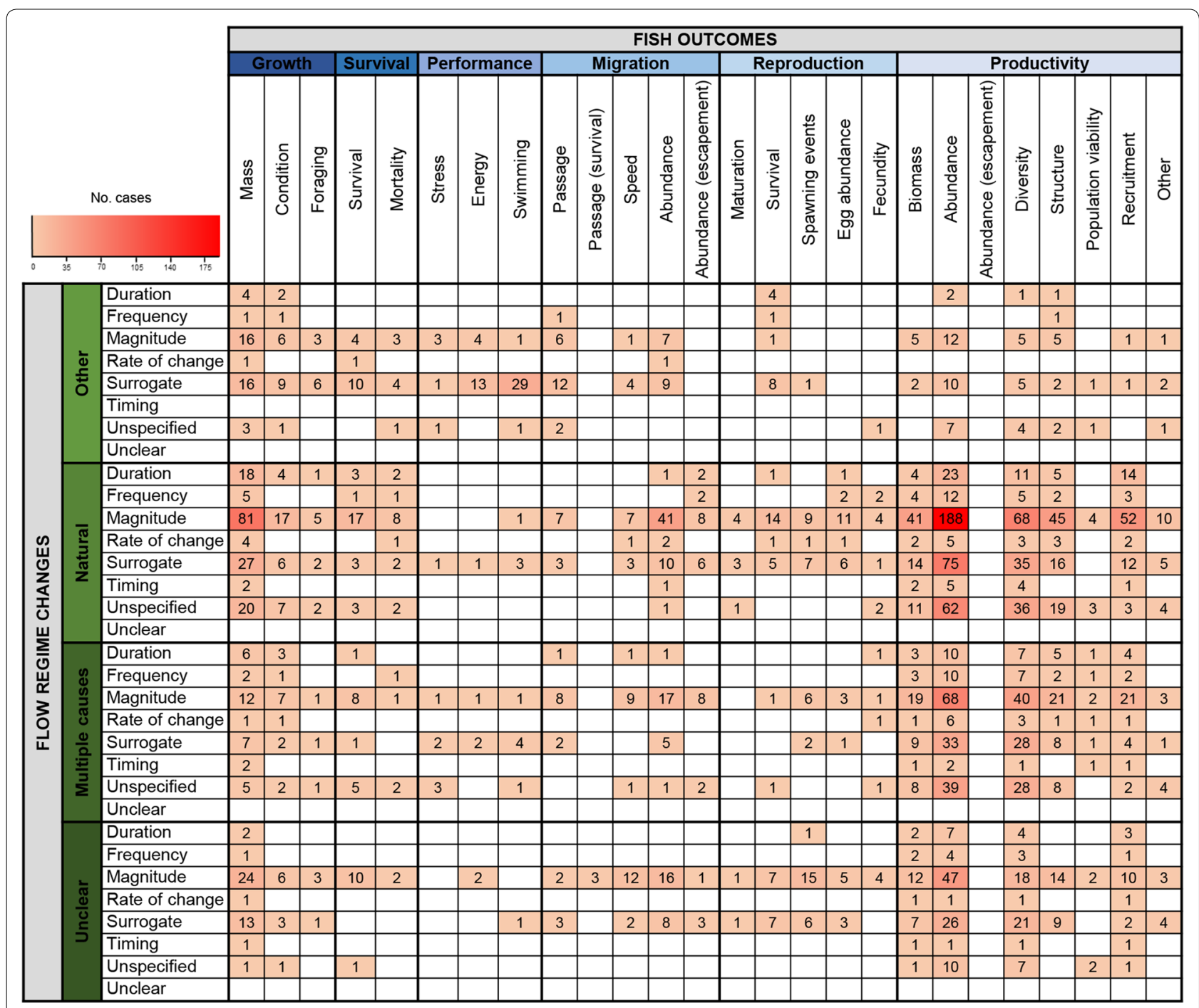

Fig. 14 Continued distribution and frequency of cases examining effects of flow-regime changes (grouped by the 4 remaining causes of such change) on fish productivity outcome categories and sub-categories

regime change were identified during the review process (i.e., restoration and land-use change), which did not have specific terms originally considered in our search string. Including these terms in a post hoc test in Web of Science Core Collection (WoSCC) added 68 hits to the original 10,160 hits. With a final inclusion rate of $6.3 \%$ relative to the WoSCC search results, we might predict 4 of these articles could be relevant to the review. Therefore, it does not appear that our search omitted a large proportion of the available literature. However, future updates to this map may consider including these additional terms in search for novel evidence. For water abstraction/extraction/diversion, search terms where included and scoped in our original search (i.e., Withdraw* OR Diversion\$); therefore, it is likely that this represents a 'real' gap in knowledge.

An obvious consideration of this map is that the search was limited to English language literature. We recognize that a substantial volume of literature likely exists in other languages, for example in French, Chinese, Spanish; however, we did not have the resources to conduct these searches. A total of 62 non-English articles were identified by our search strategy (i.e., had English abstracts) but were excluded (French, 19; Chinese 15; Spanish, 7; German, 5; Japanese, 5; Norwegian, 5, Russian, 2; Greek, Polish, Portuguese, Slovak, 1 each respectively). It is unclear how many of these articles would have met all the inclusion criteria; however still, the ability to include these 
untranslated articles would add strength to the accuracy of the map and any resultant syntheses.

\section{Limitations of the evidence base}

Due to the scope of the topic and the highly heterogeneous nature of the studies, this systematic map did not conduct a formal in-depth critical appraisal of internal validity. Instead, meta-data on aspects of study design and site selection were extracted from included studies to provide a very basic overview of the robustness of the evidence. It should be noted that the primary purpose of extracting this meta-data was to aid future more in-depth study validity assessments and synthesis of studies on sub-topics of interest identified from this systematic map exercise. Nevertheless, a few aspects of the evidence base were highlighted during this process.

For example, many studies lacked true comparators (Figs. 5 and 7). The vast majority of studies either used a temporal or spatial trend design i.e., looked at the relationship (e.g., correlations) between fish productivity and changes to flow across time but without a 'true' before intervention time period, or spatial trends that do not include no intervention ("zero-control") sites. Without an appropriate comparator, it is unclear whether any observed change in an outcome can be attributed to the intervention. Also, relatively few studies used a randomised selection procedure or deliberately spread samples evenly across clear potential confounders (Fig. 7). Random selection or site selection to reduce potential confounders is critical for the correct interpretation of the impact of the intervention [28, 35-37]. Without this, it is unclear whether the apparent intervention effect is due to the intervention itself or to differences between sampled sites.

This limited information on study validity only provides hints of methodological deficiencies. Without having done an in-depth study validity assessment on the included studies, we cannot provide a clear picture of the overall reliability of the evidence base or discern whether there are sufficient high-quality quantitative data to allow for meta-analyses in any future resultant syntheses.

We estimated 12\% (167 out of the 1368 studies) of the included studies would require contacting authors to obtain necessary data for quantitative analysis because the authors combined outcome data for species, sites, and/or years. This estimate does not consider missing quantitative data such as variances or samples sizes needed for effect size measures as this information was not noted with the map.

\section{Conclusions}

The systematic map presented here provides an overview of existing evidence evaluating the effects of flow alteration, changes, or modifications on fish productivity in freshwater and estuarine fluvial environments in temperate regions. We identified a total of 1199 articles describing 1368 studies of changes to (or manipulations of) flow regime. Documented changes of flow regime were a result of various anthropogenic and natural causes, spanning a range of north and south temperate regions (43 countries). Studies aimed at assessing the potential effect of flow alterations on fish productivity outcomes focused on 2115 species from 787 genera and 195 families, and the reported outcomes were numerous and heterogenous, with 6 broad outcome groups and 26 sub-categories identified. This map reveals a number of knowledge gaps and biases in the current evidence base, including clear concentrations of research efforts on particular geographical locations, and measured effects between intervention and outcome types.

\section{Implication for policy and management}

The outputs from this systematic map (i.e., the map database and heatmap) provide an up-to date global picture of the available evidence on the measured effects between flow-regime changes and fish productivity outcomes. Given that the importance of flow management to achieve ecosystem goals has recently become a primary focus for water resource managers [8], these outputs provide a first step towards improving our understanding of the flowecosystem response for fish populations. Water resource and fish habitat managers may find the map useful to: (1) provide an indication of the extent of the current evidence base and help in deciding whether to further extract relevant information on more specific aspects of the subject for questions of national or regional importance and/ or urgency (e.g., time-sensitive issues that need answers quickly or species-specific questions); and (2) help identify areas where there may be sufficient coverage on a specific policy-relevant question to permit a full systematic review (see "Knowledge clusters" section below).

\section{Implication for research Knowledge gaps}

This map identifies a number of understudied subtopics of relevant concern to water resource managers that may correspond to knowledge gaps, which could benefit from primary research (presented in no particular order).

1. Clear gaps in geographic coverage for studies in Northern Africa, and parts of Western, Central and South Asia; however, we are unclear whether gaps in Asia are true knowledge gaps or due to a language bias in the map.

2. Effects of flow-regime changes (all intervention types) due to restoration, land-use change, and water abstraction/extraction/diversion activities on fish productivity (all outcomes categories). 
3. Effects of changes to (or manipulations of) flow duration, frequency, rate of change, or timing on fish productivity (all causes, all outcomes).

4. Effects of changes to (or manipulations of) flow magnitude due to dams (no hydro) on metrics related to fish growth, survival, performance, migration, and reproduction.

5. Effects of changes to (or manipulations of) flow magnitude due to hydroelectric facilities and natural causes on metrics related to fish survival, performance, and reproduction.

6. Effects of changes to (or manipulations/alterations of) flow (all causes, all interventions) on population viability.

\section{Knowledge clusters}

This map suggests a number of subtopics that may warrant future evidence synthesis. The following questions, grouped by cause of flow-regime changes, have suitable numbers to permit full systematic reviewing, although the majority relate to evidence that, in general, has been coarsely assessed as being susceptible to bias (i.e., used trend designs that lack true comparators):

\section{Dams with no hydroelectric facilities}

1. How do changes in flow magnitude due to dams with no hydroelectric facilities affect fish abundance? (46 cases, $\sim 50 \%$ lacking true comparators).

\section{Hydroelectric facilities}

2. How do changes in flow magnitude due to hydroelectric dams affect fish abundance? (74 cases, 40\% lacking true comparators).

3. How do changes in flow magnitude due to hydroelectric dams affect fish diversity and richness? (36 cases, $\sim 25 \%$ lacking true comparators).

4. How do changes in flow magnitude due to hydroelectric dams affect fish migration metrics? [metrics related to Passage (32 cases), Speed (29), Abundance (42) with 65\%, 62\% and 67\% lacking true comparators respectively].

5. How do changes in flow magnitude due to hydroelectric dams affect fish growth (i.e., mass/length by age)? (39 cases, $\sim 40 \%$ lacking true comparators).

\section{Natural causes}

6. How do natural changes in flow magnitude affect fish abundance? (188 cases, 81\% lacking true comparators).
7. How do natural changes in flow magnitude affect fish diversity and richness? (68 cases, 78\% lacking true comparators).

8. How do natural changes in flow magnitude affect fish structure (i.e., age-class or length frequency distribution)? (45 cases, 82\% lacking true comparators).

9. How do natural changes in flow magnitude affect fish recruitment? (52 cases, $98 \%$ lacking true comparators).

10. How do natural changes in flow magnitude affect the abundance of migrating fish? (41 cases, 98\% lacking true comparators).

11. How do natural changes in flow magnitude affect fish growth (i.e., mass/length by age)? (81 cases, $\sim 85 \%$ lacking true comparators).

For identified subtopics $1-5$, studies were primarily concentrated in North America, and to a lesser extent in Europe, whereas for subtopics 6-11, studies were primarily concentrated in North America, and to a lesser extent in Europe and Oceania, with relatively few studies conducted elsewhere, limiting geographical scope of subtopics beyond these areas.

For identified subtopics related to natural causes (i.e., 6-11), most studies use a temporal trends design that looked at the relationship (e.g., correlations) between fish productivity and changes to flow across time but without a 'true' before intervention time period. While quantitative study designs using comparators are critically important to ensure reliability and robustness of evidence for impacts of interventions, arguments can be made regarding potentially important insights that could be gained from studies that look at trends over time that do not have proper comparators (when accompanied with an appropriate consideration for study validity). For example, there been several cases in which relatively unstructured, long-term monitoring has led to the discovery of ecological change or corroboration of hypotheses for a variety of ecological phenomena and conservation issues (e.g., [38-40]). Here, for example, one could explore changes in flow magnitude over time in different regions with time series analysis to address the question: What is the relationship between natural changes in flow magnitude and fish abundance? Potential sources of heterogeneity related to regional climatic differences and/or physical characteristics of the catchment at these locations could also be investigated. We acknowledge there are possible logistical challenges involved with such an undertaking. First, this would require obtaining raw data from most studies for proper assessment, and possibly limit the number of studies that can be included if 
the response rate from authors is low. Second, extreme flow characteristics are often influenced substantially by the temporal and spatial extent of the observation records [41, 42], and definitions and quantifications of flow events are highly variably (see Garner et al. [43]), making standardization across studies challenging. Nevertheless, with careful consideration for these challenges, these studies could further contribute useful information and provide a more comprehensive knowledge base on the subject.

It should also be noted that the choice of outcome (Table 3) to act as a surrogate or indicator of fish productivity is typically based on project objectives (e.g., impact on individuals, population, community), the site characteristics (e.g., open or closed system, stream vs. river), and the species or community to be sampled. Indicators vary in their sensitivity or response to a change in the environment, and in their specificity, natural variability, response time, ease of measurement and cost, all factors which should be considered in their selection for an individual study [44]. Thus, when conducting a comparative analysis among disparate studies (such as in a meta-analysis), a range of indicators could be available that may or may not be suitable for combination. For example, combining indicators of individual components of productivity such as growth, survival, reproduction, or individual performance (see Bradford et al. [45]) in a meta-analysis with indicators of fish populations (e.g., abundance, biomass, diversity) would not be suitable. In addition, even when dealing with similarly-scaled indicators, care must be taken to ensure they are suitable for comparison. For example, the population level metric of 'abundance' could include simple count data with no correction for effort or detection probability, relative count data such as catchper-unit-effort, or absolute density estimated from a mark-recapture study (i.e., \#/unit area). These measures have different levels of precision in their relationship to productivity. Therefore, all of the factors listed above should be carefully considered when combining data into a quantitative analysis.

In general, with this map a significant proportion of the work has been completed towards producing full systematic reviews; the time-consuming stages of full systematic review have been completed (i.e., searching, screening, and meta-data extraction of full-texts). Remaining work for the above questions: (1) updated search, including calls for evidence in search of novel evidence pertinent to the review questions above; (2) screening of novel evidence found from updated search; (3) full data extraction (to supplement extracted meta-data from map); (4) full study validity assessment; and (5) quantitative synthesis when possible.

\section{Supplementary information}

Supplementary information accompanies this paper at https://doi. org/10.1186/s13750-020-00190-z.

Additional file 1. Search strategy and results. A description of our search strategy and the results of the literature searches. For each source, we provide full details on the search date(s), search strings used, search settings/ restrictions, and subscriptions (if applicable), and the number of returns.

Additional file 2. Lists of articles excluded on the basis of full-text assessment with reasons for exclusion and unobtainable articles. Separate lists of articles excluded on the basis of full-text assessment and articles that were unobtainable.

Additional file 3. Additional study validity assessment details related to degree of replication. We provide additional information as to how we evaluated studies for their degree of true replication for study validity assessments.

Additional file 4. Systematic map database. Contains the coding (extracted data) for all articles/studies included in the map. Includes a description of the coding form, the actual coding of all articles/studies, and a codes sheet.

Additional file 5. List of relevant reviews. A full list of all relevant reviews.

Additional file 6. ROSES Systematic map checklist.

Additional file 7. List of associated synonyms of species names and irregularities used in included studies. Here we provide lists of associated synonyms of species names used in included studies as well as irregularities.

\section{Acknowledgements}

The authors would like to thank Daniel Struthers for help with website searches and pdf retrieval. We also thank Shannon Clarke, D. Struthers, Emily Way-Nee, Teah Lizee, Jill Brooks, and Laura Elmer for assisting with screening of articles and websites. We also thank the reviewers for their constructive comments.

\section{Authors' contributions}

TR undertook the searches, screening, and TR and MH conducted coding of articles and study validity assessments. This review is based on a draft written by TR. MH participated in the drafting and revision of the manuscript. All authors assisted in the design of protocol methodology, editing and revising the manuscript. All authors read and approved the final manuscript.

\section{Funding}

The study was primarily supported by Fisheries and Oceans Canada. Additional support is provided by the Natural Science and Engineering Research Council of Canada, The Canada Research Chairs Program, and Carleton University.

\section{Availability of data and materials}

All data generated or analysed during this study are included in this published article and additional files. A ROSES form [46] for this systematic map report is included as Additional file 6.

Ethics approval and consent to participate

Not applicable.

\section{Consent for publication}

Not applicable.

\section{Competing interests}

The authors declare that they have no competing interests.

\section{Author details}

${ }^{1}$ Canadian Centre for Evidence-Based Conservation, Institute of Environmental and Interdisciplinary Science, Carleton University, Ottawa, ON, Canada. ${ }^{2}$ Fish Ecology and Conservation Physiology Laboratory, Department of Biology, Carleton University, Ottawa, ON, Canada. ${ }^{3}$ Department of Biology 
and Institute of Environmental and Interdisciplinary Science, Carleton University, Ottawa, ON, Canada. ${ }^{4}$ Great Lakes Laboratory for Fisheries and Aquatic Sciences, Fisheries and Oceans Canada, Sault Ste. Marie, ON, Canada.

${ }^{5}$ Northwest Atlantic Fisheries Centre, Fisheries and Oceans Canada, St. John's, NF, Canada. ${ }^{6}$ West Vancouver Laboratory, Fisheries and Oceans Canada, West Vancouver, BC, Canada. ${ }^{7}$ Freshwater Institute, Fisheries and Oceans Canada, 501 University Cres, Winnipeg, MB, Canada. ${ }^{8}$ School of Aquatic and Fishery Sciences, University of Washington, Seattle, WA, USA. ${ }^{9}$ Départment de sciences biologiques, Université de Montréal, Montréal, QC, Canada.

Received: 1 November 2019 Accepted: 7 April 2020

\section{Published online: 18 April 2020}

\section{References}

1. Power ME, Sun A, Parker G, Dietrich WE, Wootton JT. Hydraulic food-chain models. Bioscience. 1995:45:159-67.

2. Poff NL, Allan JD, Bain MB, Karr JR, Prestegaard KL, Richter BD, et al. The natural flow regime: a paradigm for river conservation and restoration. Bioscience. 1997:47:769-84.

3. Bunn SE, Arthington AH. Basic principles and ecological consequences of altered flow regimes for aquatic biodiversity. Environ Manag. 2002:30:492-507.

4. Olden JD, Poff NL. Redundancy and the choice of hydrologic indices for characterizing streamflow regimes. River Res Appl. 2003;19:101-21.

5. Naiman RJ, Latterell JJ, Pettit NE, Olden JD. Flow variability and the biophysical vitality of river systems. CR Geosci. 2008;340:629-43.

6. Lytle DA, Poff NL. Adaptation to natural flow regimes. Trends Ecol Evol. 2004;19:94-100.

7. Mims MC, Olden JD. Life history theory predicts streamflow effects on fish assemblage response to hydrologic regimes. Ecology. 2012;2012(93):35-45.

8. Gillespie BR, Desmet S, Kay P, Tillotson MR, Brown LE. A critical analysis of regulated river ecosystem responses to managed environmental flows from reservoirs. Freshw Biol. 2015;60:410-25.

9. Grill G, Lehner B, Thieme M, Geenen B, Tickner D, Antonelli F, et al. Mapping the world's free-flowing rivers. Nature. 2019;569:215-21.

10. Gleick PH. Global freshwater resources: soft-path solutions for the $21 \mathrm{st}$ century. Science. 2003;302:1524-8

11. Enders EC, Scruton DA, Clarke KD. The 'Natural Flow Paradigm' and Atlantic salmon-moving from concept to practice. River Res Appl. 2009;25:2-15.

12. Poff NL, Zimmerman JKH. Ecological responses to altered flow regimes: a literature review to inform the science and management of environmental flows. Freshw Biol. 2010;55:194-205.

13. Junk WJ, Bayley PB, Sparks RE. The flood pulse concept in river-floodplain systems. In: Proceedings of the international large river symposium (LARS)_Can Spec Publ Fish Aquat Sci, vol. 106. 1989; p. 110-27.

14. Lake PS. Disturbance, patchiness, and diversity in streams. J N Am Benthol Soc. 2000;19:573-92.

15. Resh VH, Brown AV, Covich AP, Gurtz ME, Li HW, Minshall GW, et al. The role of disturbance in stream ecology. J N Am Benthol Soc. 1988;7:433-55.

16. Ledger ME, Milner AM. Extreme events in running waters. Freshw Biol. 2015;60:2455-60.

17. McManamay RA, Orth DJ, Kauffman J, Davis MM. A database and metaanalysis of ecological responses to stream flow in the South Atlantic Region. Southeast Nat. 2013;12:1-36.

18. Piniewski M, Prudhomme C, Acreman MC, Tylec L, Oglęcki P, Okruszko T. Responses of fish and invertebrates to floods and droughts in Europe. Ecohydrology. 2017;10:e1793.

19. Clark KD, Pratt TC, Randall RG, Scruton DA, Smokorowski KE. Validation of the flow management pathway: effects of altered flow on fish habitat and fishes downstream from a hydropower dam. DFO CanTech Rep Fish Aquat Sci. 2008. http://www.dfo-mpo.gc.ca/Library/332113.pdf. Accessed 6 Oct 2016

20. Murchie KJ, Hair KPE, Pullen CE, Redpath TD, Stephens HR, Cooke SJ. Fish response to modified flow regimes in regulated rivers: research methods, effects and opportunities. River Res Appl. 2008;24:197-217.
21. Webb JA, Miller KA, King EL, de Little SC, Stewardson MJ, Zimmerman $J \mathrm{KH}$, Poff NL. Squeezing the most out of existing literature: a systematic re-analysis of published evidence on ecological responses to altered flows. Freshw Biol. 2013;58:2439-51.

22. Haxton T, Findlay CS. Meta-analysis of the impacts of water management on aquatic communities. Can J Fish Aquat Sci. 2010;65(3):437-47.

23. Scruton DA, Clarke KD, Roberge MM, Kelly JF, Dawe MB. A case study of habitat compensation to ameliorate impacts of hydroelectric development: effectiveness of re-watering and habitat enhancement of an intermittent flood overflow channel. J Fish Biol. 2005;67:244-60.

24. King J, Brown C. Environmental flows: striking the balance between development and resource protection. Ecol Soc. 2006;11:26.

25. Pittock J, Lankford BA. Environmental water requirements: demand management in an era of water scarcity. J Integr Environ Sci. 2010;7:75-93.

26. Tonkin JD, Poff NL, Bond NR, Horne A, Merritt DM, Olden JD, et al. Preparing river ecosystems for an uncertain future. Nature. 2019;570:301-3.

27. Rytwinski T, Taylor JJ, Bennett JR, Smokorowski KE, Cooke SJ. What are the impacts of flow regime changes on fish productivity? A systematic map protocol. Environ Evid. 2017;6:13.

28. Collaboration for Environmental Evidence. In: Pullin AS, Frampton GK, Livoreil B, Petrokofsky G, editors. Guidelines and standards for evidence synthesis in environmental management. Version 5.0. 2018. http://www. environmentalevidence.org/information-for-authors. Accessed 31 May 2018.

29. Rytwinski T, Taylor JJ, Donaldson LA, Bennett JR, Hinch SG, Cooke SJ. Do fish passage facilities and culverts promote fish movement at barriers? A systematic review protocol. Open Science Framework. 2018. https://osf. io/xvzbf/. Accessed 30 Oct 2018

30. Haddaway NR, Styles D, Pullin AS. Evidence on the environmental impacts of farm land abandonment in high altitude/mountain regions: a systematic map. Environ Evid. 2014;3:17.

31. Cresswell CJ, Cunningham HM, Wilcox A, Randall NP. What specific plant traits support ecosystem services such as pollination, bio-control and water quality protection in temperate climates? a systematic map. Environ Evid. 2018;7:2

32. Froese R, Pauly D, editors. FishBase. 2019. http://www.fishbase.org. Accessed June 2019.

33. Fricke R, Eschmeyer WN, Van der Laan R, editors. Eschemeyer's catalog of fishes: genera, species, references (electronic version). 2019. http://resea rcharchive.calacademy.org/research/ichthyology/catalog/fishcatmai n.asp. Accessed June 2019.

34. Haddaway NR, Macura B, Whaley P, Pullin AS. ROSES flow diagram for systematic maps. Version 1.0. figshare. 2017. https://doi.org/10.6084/ m9.figshare.6085940.

35. Kunz R, Oxman AD. The unpredictability paradox: review of empirical comparisons of randomised and non-randomised trials. Br Med J. 1998;317:1185-90.

36. Rytwinski T, van der Ree R, Cunnington G, Fahrig L, Findlay S, Houlahan J, Jaeger JAG, Soanes K, van der Grift EA. Experimental study designs to improve the evaluation of road mitigation measures for wildlife. J Environ Manag. 2015;154:48-64

37. Cooke SJ, Birnie-Gauvin K, Lennox RJ, Taylor JJ, Rytwinski T, Rummer JL, Franklin CE, Bennett JR, Haddaway NR. How experimental biology and ecology can support evidence-based decision-making in conservation: avoiding pitfalls and enabling application. Conserv Physiol. 2017:5:1.

38. Doak DF, Estes JA, Halpern BS, Jacob U, Lindberg DR, Lovvorn J, et al. Understanding and predicting ecological dynamics: are major surprises inevitable? Ecology. 2008;89:952-61.

39. Wintle BA, Runge MC, Bekessy SA. Allocating monitoring effort in the face of unknown unknowns. Ecol Lett. 2010;13:1325-77.

40. Lindermayer DB, Likens GE, Andersen A, Bowman D, Bull CM, Burns E, et al. Value of long-term ecological studies. Austral Ecol. 2012;37:745-57.

41. Hannaford J, Buys G, Stahl K, Tallaksen LM. The influence of decadal-scale variability on trends in long European streamflow records. Hydrol Earth Syst Sci. 2013;17:2717-33.

42. Hall J, Arheimer B, Borga M, Brázdil R, Claps P, Kiss A, et al. Understanding flood regime changes in Europe: a state-of-the-art assessment. Hydrol Earth Syst Sci. 2014;18:2735-72.

43. Garner G, Van Loon AF, Prudhomme C, Hannah DM. Hydroclimatology of extreme river flows. Freshw Biol. 2015;60:2461-76. 
44. Braun DC, Smokorowski KE, Bradford MJ, Glover L. A review of functional monitoring methods to assess mitigation, restoration, and offsetting activities in Canada. Department of Fisheries and Oceans, Canadian Science Advisory Secretariat Research Document; 2019. p. 57 vii +75 p.

45. Bradford MJ, Randall RG, Smokorowski KS, Keatley BE, Clarke KD. A framework for assessing fisheries productivity for the Fisheries Protection Program. Department of Fisheries and Oceans, Canadian Science Advisory Secretariat Research Document; 2014. p. $67 v+25$ p.
46. Haddaway N, Macura B, Whaley P, Pullin A. ROSES for systematic map reports. Version 1.0. figshare. 2017. https://doi.org/10.6084/m9.figsh are.5897299.

\section{Publisher's Note}

Springer Nature remains neutral with regard to jurisdictional claims in published maps and institutional affiliations.
Ready to submit your research? Choose BMC and benefit from:

- fast, convenient online submission

- thorough peer review by experienced researchers in your field

- rapid publication on acceptance

- support for research data, including large and complex data types

- gold Open Access which fosters wider collaboration and increased citations

- maximum visibility for your research: over $100 \mathrm{M}$ website views per year

At BMC, research is always in progress.

Learn more biomedcentral.com/submissions 